\title{
The genus Synaldis Foerster, 1863 (Hymenoptera: Braconidae: Alysiinae) in the Neotropical region: first record, descriptions of new species and a key to the New World taxa
}

\author{
Francisco Javier PERIS-FELIPO ${ }^{1, *}$ \& Sergey A. BELOKOBYLSKIJ ${ }^{2}$ \\ ${ }^{1}$ Bleichestrasse 15, CH-4058 Basel, Switzerland. \\ ${ }^{2}$ Zoological Institute, Russian Academy of Sciences, St Petersburg, 199034, Russia; Museum and \\ Institute of Zoology, Polish Academy of Sciences, Wilcza 64, Warszawa 00-679, Poland. \\ *Corresponding author: peris.felipo@gmail.com \\ 2Email: doryctes@gmail.com \\ ${ }^{1}$ urn:1sid:zoobank.org:author:C7B698F7-0A6A-4C4A-915F-8D5ACC380853 \\ ${ }^{2}$ urn:lsid:zoobank.org:author:13EDEDEF-68BA-430B-8FC3-0096874859AB
}

\begin{abstract}
The genus Synaldis Foerster, 1863 is recorded in the Neotropical region for the first time. Five new Neotropical species, S. brasiliense Peris-Felipo, sp. nov., S. fritzi Peris-Felipo, sp. nov., S. longiflagellaris Peris-Felipo, sp. nov., S. magnioculis Peris-Felipo, sp. nov., and S. novateutoniae Peris-Felipo, sp. nov., are described and illustrated. The original combination for Synaldis ulmicola Ashmead, 1889 stat. rev. is proposed. A key for the determination of the all New World Synaldis species is provided.
\end{abstract}

Key words. Braconidae, Alysiinae, Synaldis, Nearctic and Neotropical regions, new species, key.

Peris-Felipo F.J. \& Belokobylskij S.A. 2017. The genus Synaldis Foerster, 1863 (Hymenoptera: Braconidae: Alysinae) in the Neotropical region: first record, descriptions of new species and a key to the New World taxa. European Journal of Taxonomy 386: 1-28. https://doi.org/10.5852/ejt.2017.386

\section{Introduction}

The status of the Alysiinae genus Synaldis Foerster, 1863 has been uncertain for a long time. Van Achterberg (1988) revised the Aspilota genera group and synonymized this genus with the re-established genus Dinotrema Foerster, 1863 on the basis of the plesiomorphic state of the unenlarged paraclypeal pits. As a result, he distributed the former species of Synaldis among the genera Aspilota Foerster, 1863 and Dinotrema according to the new diagnostic feature, the size of the paraclypeal areas. However, such a synonymy of Synaldis was not supported by several experts working on alysiine taxa (Fischer 1993a, 1993b; Papp 2000; Belokobylskij 2002). It is necessary to underline that such an apomorphic feature, as the complete reduction of vein 2-SR, is an evolutionary event which was also accompanied by the disappearance of the break (corner) between veins $r$ and 3-SR, this part of the veins is only gently and relatively widely curved. Such an apomorphic state of the wing venation represents an important qualitative transformation and can reliably support the generic status of Synaldis (Belokobylskij 2002) 
in spite of the rare present reduction of vein 2-SR in some specimens of a few species of Dinotrema. For that reason, we prefer to keep the generic status for Synaldis until any results of a molecular phylogenetic study of taxa of Alysiinae. Rather recently, Fischer (2003) established the genus Adelphenaldis, whose species differ from Synaldis only by the length of the paraclypeal fovea, which reaches the margin of the eye in Adelphenaldis, and is thus equivalent to the species of 'Synaldis' that Van Achterberg (1988) placed in Aspilota. Peris-Felipo \& Belokobylskij (2016) published a key for the identification of these four related genera.

The genus Synaldis comprises about a hundred species described in the Afrotropical, Oriental, Australasian, Oceanic, Nearctic and Palaearctic regions (Fischer 1962, 1967a, 1967b, 1971, 1993a, 1993b, 2003; Belokobylskij 2002, 2004a, 2004b; Belokobylskij \& Tobias 2007; Peris-Felipo et al. 2014b). The genus, however, had not been discovered in the Neotropical region until the present work.

Members of the genus Synaldis are often reared from agaric mushrooms and recorded as parasitoids of the larvae and puparia of the dipterous families Phoridae (mainly) and Drosophilidae (doubtfully) (Hussey 1960; Fischer 2005; Yu et al. 2012).

In this paper, the genus Synaldis is recorded for the first time from the Neotropical region. Five new Neotropical species, S. brasiliense Peris-Felipo, sp. nov., S. fritzi Peris-Felipo, sp. nov., S. longiflagellaris Peris-Felipo, sp. nov., S. novateutoniae Peris-Felipo, sp. nov. and S. magnioculis Peris-Felipo, sp. nov., are described and illustrated. The combination, Synaldis ulmicola Ashmead, 1889 stat. rev., is also proposed after type revision. The records of the Nearctic species S. cabinica Fischer, 1967 in Korea and Russia (Far East) (Papp 1996; Belokobylskij 2002) and S. exitiosae Fischer, 1967 in Turkey (Beyarslan \& Inanç 1992) are very doubtful and we exclude these regions in the distributions in our key.

\section{Materials and methods}

For the terminology of morphological features, sculpture and measurements see Peris-Felipo et al. (2014a); for wing venation nomenclature see Van Achterberg (1993); for measurements of the marginal cell see Fig. 1.

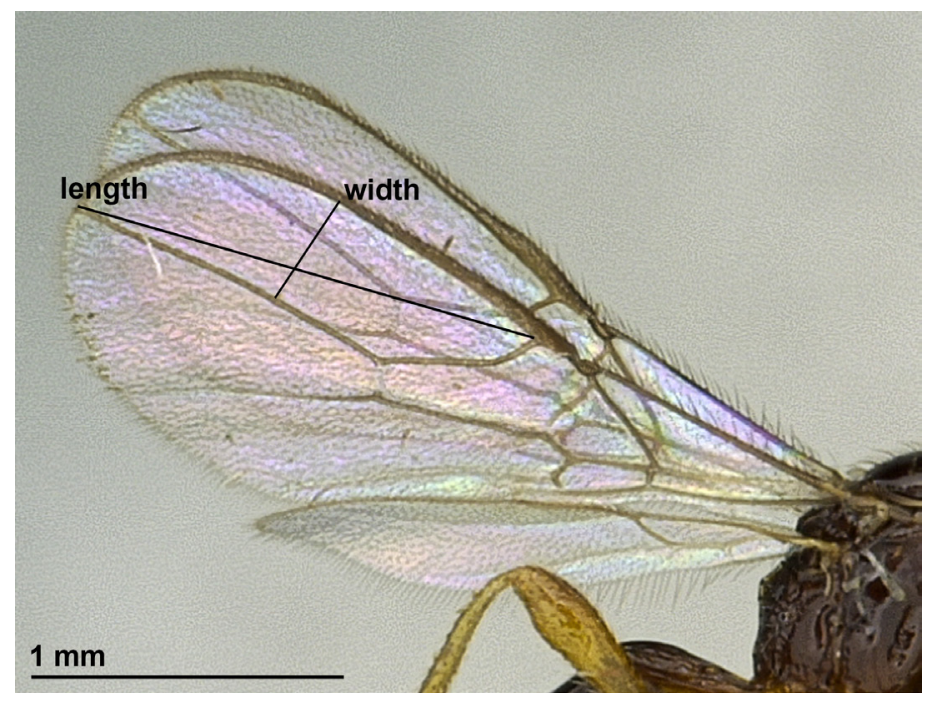

Fig. 1. Marginal cell of fore wing, measurements. 
Table 1. A list of studied type material of the previously described New World species and place of their preservation. * This species was originally described as Synaldis ulmicola by Ashmead (1889), however Fischer (1967b) placed it in the genus Aspilota as Aspilota ulmicola. After revision of the holotype we consider it to belong within the genus Synaldis by the absence of vein 2-SR.

\begin{tabular}{|c|c|c|c|}
\hline Studied species & Status of type & Sex & Place of preservation \\
\hline Synaldis acutidens Fischer, 1967 & Paratype & q & NHMW \\
\hline Synaldis alfalfae Fischer, 1967 & Paratype & 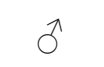 & NHMW \\
\hline Synaldis altera Fischer, 1967 & Paratype & $0^{\pi}$ & NHMW \\
\hline Synaldis blantoni Fischer, 1967 & Holotype & $\hat{0}$ & NMNH \\
\hline Synaldis cabinica Fischer, 1967 & Paratype & q & NHMW \\
\hline Synaldis difficilis Fischer, 1967 & Paratype & $\hat{0}$ & NHMW \\
\hline Synaldis exitiosae Fischer, 1967 & Paratype & +,$\hat{0}$ & NHMW \\
\hline Synaldis glabrifovea Fischer, 1967 & Paratype & q & NHMW \\
\hline Synaldis incisa Gahan, 1912 & Paratype & 우 & NHMW \\
\hline Synalids liliputana Fischer, 1967 & Holotype & 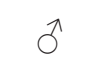 & NMNH \\
\hline Synaldis megaseliae Fischer, 1967 & Paratype & q & NHMW \\
\hline Synaldis numerosa Fischer, 1967 & Paratype & $q$ & NHMW \\
\hline Synaldis painteri Fischer, 1967 & Paratype & +,$\hat{0}$ & NHMW \\
\hline Synaldis pygmaea Viereck, 1917 & Holotype & $\hat{o}$ & $\mathrm{NMNH}$ \\
\hline Synaldis quinnipiacorum Viereck, 1917 & Holotype & q & NMNH \\
\hline Synaldis rotudidens Fischer, 1967 & Paratype & $0^{\lambda}$ & NHMW \\
\hline Synaldis segmentata Fischer, 1967 & Holotype & q & NMNH \\
\hline Synaldis spiraculosa Fischer, 1967 & Holotype & q & NMNH \\
\hline Synaldis ulmicola Ashmead, 1889* & Holotype & q & NMNH \\
\hline
\end{tabular}

Material was imaged using a Digital Microscope Keyence ${ }^{\circledR}$ VHX-2000 and Adobe Photoshop ${ }^{\circledR}$ imaging system. The types of described and studied species are deposited in the collections listed below and in Table 1:

BMNH $=$ Natural History Museum (London, UK)

NHMW $=$ Naturhistorisches Museum Wien (Austria)

$\mathrm{NMNH}=$ Smithsonian National Museum of Natural History (USA)

ZISP $=$ Zoological Institute of the Russian Academy of Sciences (St Petersburg, Russia)

\section{Results}

\section{Taxonomic treatment}

Five new Neotropical species of the genus Synaldis are described and illustrated: S. brasiliense PerisFelipo, sp. nov., S. fritzi Peris-Felipo, sp. nov., S. longiflagellaris Peris-Felipo, sp. nov., S. magnioculis Peris-Felipo, sp. nov. and S. novateutoniae Peris-Felipo, sp. nov. S. magnioculis Peris-Felipo, sp. nov. The type material of the Nearctic species deposited in the Smithsonian Institution (Washington, USA; NMNH) and the Naturhistorisches Museum (Wien, Austria; NHMW) were revised; a new combination for previously member of Aspilota genus, Synaldis ulmicola Ashmead, 1889 stat. rev. is suggested. 
Class Hexapoda Blainville, 1816

Order Hymenoptera Linnaeus, 1758

Family Braconidae Nees, 1811

Subfamily Alysiinae Leach, 1815

Tribe Alysiini Leach, 1815

Genus Synaldis Foerster, 1863

\section{Diagnosis}

Mandibles tridentate, teeth of differing shape and length. Paraclypeal fovea short, far from reaching ventral margin of eye. Mesoscutal pit present or absent. Precoxal sulcus always present, usually not reaching anterior and posterior margins of mesopleuron. Pterostigma very long and narrow. Vein 2-SR always absent; break between veins $r$ and 3-SR absent and abscissae here only gently and rather widely curved. Veins m-cu and cu-a always postfurcal.

\section{Hosts}

Diptera larvae, mainly of the family Phoridae and possibly Drosophilidae.

Synaldis brasiliense Peris-Felipo, sp. nov. urn:1sid:zoobank.org:act:155AA0A3-2442-44DD-9097-75A9F1E054E6

Figs $2-3$

\section{Diagnosis}

This new species is similar to S. glabrifovea Fischer, 1967 (USA), but differs from it in having the prescutellar pit present (absent in S. glabrifovea), face 2.1 times as long as high (3.0 times in S. glabrifovea), mandible 1.8 times as long as its maximum width (1.5 times in S. glabrifovea), and the first metasomal tergite 2.4 times as long as its apical width (2.1 times in S. glabrifovea).

\section{Etymology}

The specific epithet refers to "Brazil", after the country where this species was found.

\section{Material examined}

\section{Holotype}

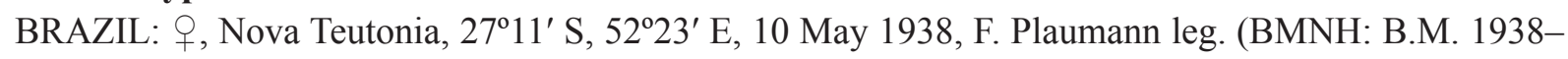
682).

\section{Paratypes}

BRAZIL: 1 q, 1 ก, same locality, but $27^{\circ} \mathrm{S}, 52-58^{\circ}$ E, 28 May and 1 Jun. 1938, F. Plaumann leg. (BMNH: B.M. 1938-458).

\section{Description}

Female (holotype)

Length. Body $1.7 \mathrm{~mm}$, fore wing $2.1 \mathrm{~mm}$, hind wing $1.4 \mathrm{~mm}$.

CoLour. Body, pterostigma and flagellar segments of antenna brown, scape and pedicel brownish yellow. Basal part of pronotal sides and propleuron yellow. First metasomal tergite similar colour to second and third tergites. Legs yellow. Wings hyaline. 
HeAD. In dorsal view, 1.8 times as wide as long, 1.5 times as wide as mesoscutum, smooth, with temple rounded behind eyes. Eye in lateral view 1.5 times as high as wide and 1.4 times as wide as temple medially. POL 1.3 times as long as OD; OOL 3.2 times OD. Face 2.1 times as wide as high; inner margins of eyes subparallel. Clypeus 3.0 times as wide as high, slightly concave ventrally. Paraclypeal fovea reaching half of distance between clypeus and eye. Mandible narrow, not widened towards apex, 1.8 times as long as its maximum width. Upper tooth very small, distinctly shorter than middle tooth; middle tooth small, pointed apically; lower tooth short, as long as upper tooth, rounded. Antennae 20-segmented, 1.2 times as long as body. Scape 1.5 times as long as pedicel. First flagellar segment 3.6
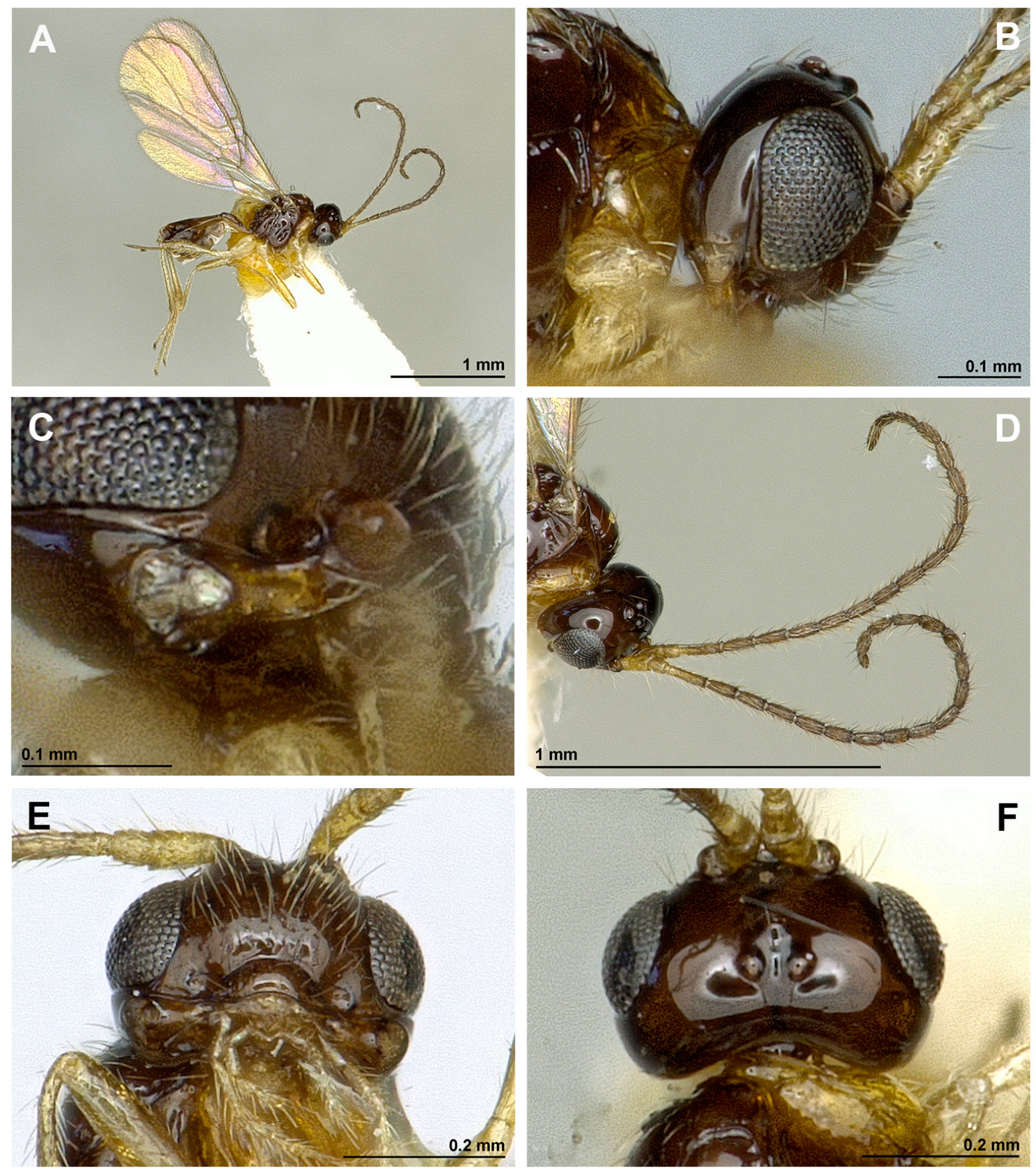

Fig. 2. Synaldis brasiliense Peris-Felipo, sp. nov., ${ }_{+}$. A. Habitus, lateral view. B. Head, lateral view. C. Mandible. D. Antenna. E. Face, front view. F. Head, dorsal view. 
times as long as its apical width, 1.2 times as long as second segment. Second to $4^{\text {th }}$ segments 2.7 times, $5^{\text {th }}$ to seventh segments 2.2 times, $9^{\text {th }}$ to $15^{\text {th }}$ segments 2.1 times, $16^{\text {th }}$ segment 2.0 times, $17^{\text {th }}$ segment 1.8 times and $18^{\text {th }}$ (apical) segment 2.3 times as long as their maximum width.

Mesosoma. In lateral view 1.2 times as long as high. Mesoscutum (dorsal view) 0.9 times as long as its maximum width, with sparse setae arranged as single line along notaulus line. Notauli mainly absent on horizontal surface of mesoscutum. Mesoscutal pit present and elongate. Prescutellar depression smooth,
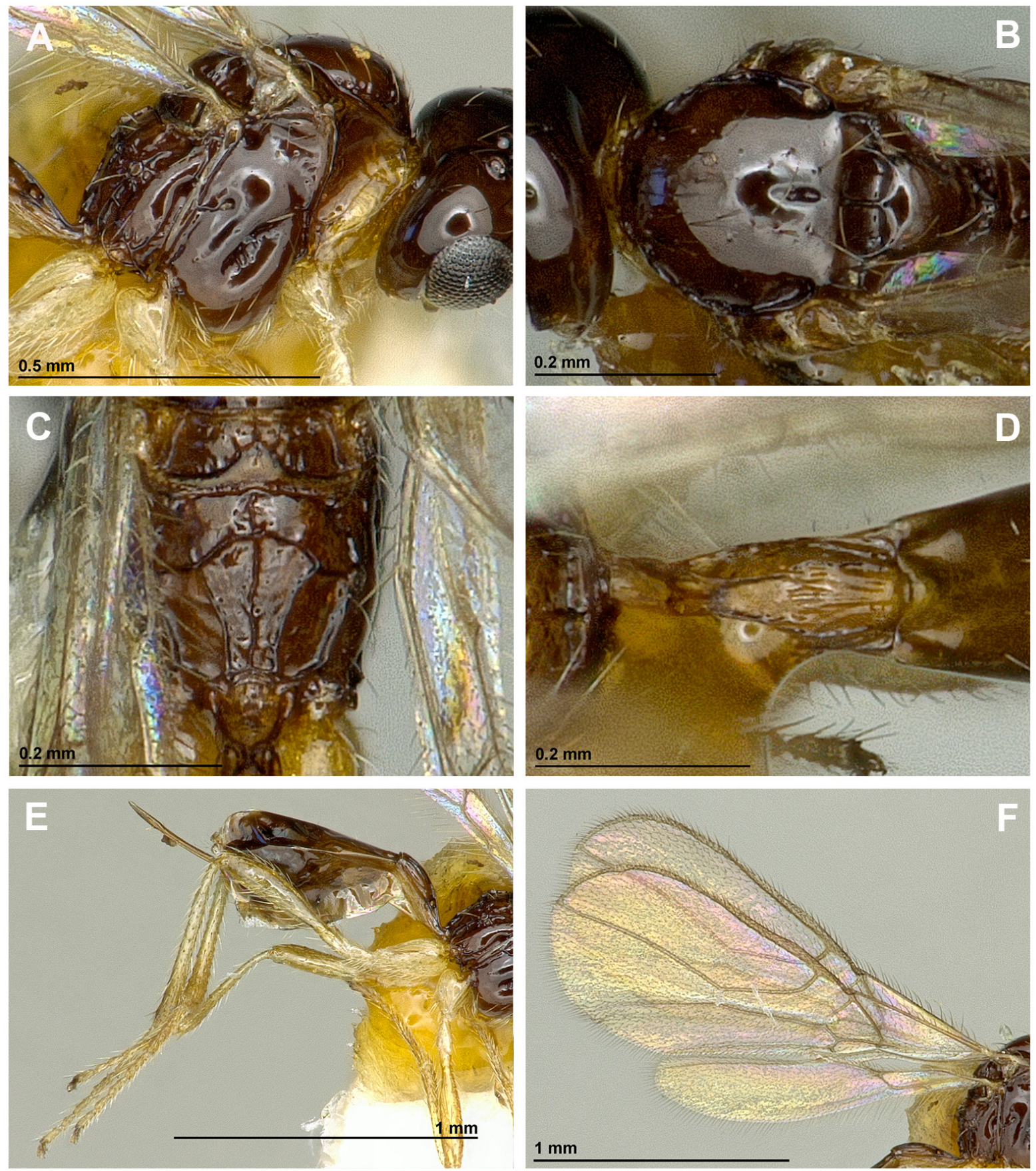

Fig. 3. Synaldis brasiliense Peris-Felipo, sp. nov., + . A. Mesosoma, lateral view. B. Mesonotum, dorsal view. C. Propodeum. D. First metasomal tergite. E. Legs, metasoma and ovipositor, lateral view. F. Fore and hind wings. 
without lateral carinae, 1.1 times as long as its maximum width. Precoxal sulcus present, crenulate, not reaching anterior and posterior margins of mesopleuron. Posterior mesopleural furrow smooth. Propodeum with pentagonal areola crossed by complete and distinct median longitudinal carina from its base to apex. Propodeal spiracles relatively small, its diameter 0.2 times as wide as the distance from spiracle to anterior margin of propodeum.

Wings. Length of fore wing 2.8 times its maximum width. Marginal cell ending on apex of wing, 4.0 times as long as its maximum width. Vein SR1 2.5 times as long as vein 3-SR. Vein 3-SR 3.0 times as long as vein r. Vein cu-a distinctly postfurcal. First subdiscal cell closed distally, 3.0 times as long as its maximum width. Hind wing 5.7 times as long as its maximum width.

LEGS. Hind femur 4.1 times as long as its maximum width. Hind tibia weakly widened to apex, 8.4 times as long as its maximum subapical width, about as long as hind tarsus. First segment of hind tarsus 1.5 times as long as second segment.

Metasoma. First tergite weakly widened towards apex, 2.4 times as long as its apical width, weakly striate in apical half. Ovipositor 1.3 times as long as first tergite, 0.4 times as long as metasoma, 0.8 times as long as hind femur.

VARIATION. Body 1.5-1.7 mm; fore wing 2.0-2.2 mm; hind wing 1.3-1.5 mm. Hind femur 4.0-4.2 times as long as its maximum width. First flagellar segment 3.6-3.7 times as long as its apical width, and second segment 2.2-2.3 times.

\title{
Male
}

Body length $1.6 \mathrm{~mm}$, fore wing $1.9 \mathrm{~mm}$, hind wing $1.3 \mathrm{~mm}$. Antenna 21 -segmented, 1.3 times as long as body. Second flagellar segment 3.2 times as long as its maximum width and 6th segment 2.3 times. Hind femur 4.4 times as long as its maximum width. Otherwise similar to female.

\author{
Synaldis fritzi Peris-Felipo, sp. nov. \\ urn:lsid:zoobank.org:act:AB4D5992-A719-41BA-AC52-A953848ECD10
}

Figs $4-5$

\section{Diagnosis}

This new species is similar to $S$. magnioculis sp. nov. but differs from it in having the eye in lateral view 1.5 times as long as temple medially (1.7 times in S. magnioculis sp. nov.), face 1.8 times as long as high (1.2 times in $S$. magnioculis sp. nov.), second flagellar segment 2.2 times as long as its maximum width (2.7 times in S. magnioculis sp. nov.); sixth segment 1.8 times (2.5 times in S. magnioculis sp. nov.), and hind femur 3.5 times as long as its maximum width (3.9 times in S. magnioculis sp. nov.).

\section{Etymology}

Named after Fritz Plaumann, collector of the type material of this new species.

\section{Material examined}

\section{Holotype}

BRAZIL: +, Nova Teutonia, 27¹1' S, 52²3' E, 20 Aug. 1937, F. Plaumann leg. (BMNH: B.M. 1937748).

\section{Paratypes}

BRAZIL: 3 +,+ 1 ô, same locality as holotype, but 19 Mar., 5 Jul., 31 Aug. 1937 and 2 Jun. 1938 (BMNH, ZISP: B.M. 1937-424; 1937-656; 1937-748; 1938-458). 


\section{Description}

Female (holotype)

LENGTH. Body $2.7 \mathrm{~mm}$, fore wing $2.7 \mathrm{~mm}$, hind wing $1.8 \mathrm{~mm}$.

Colour. Body, flagellar segments of antenna and pterostigma brown. Legs brownish yellow. First metasomal tergite similar colour to second and third tergites. Wings hyaline.
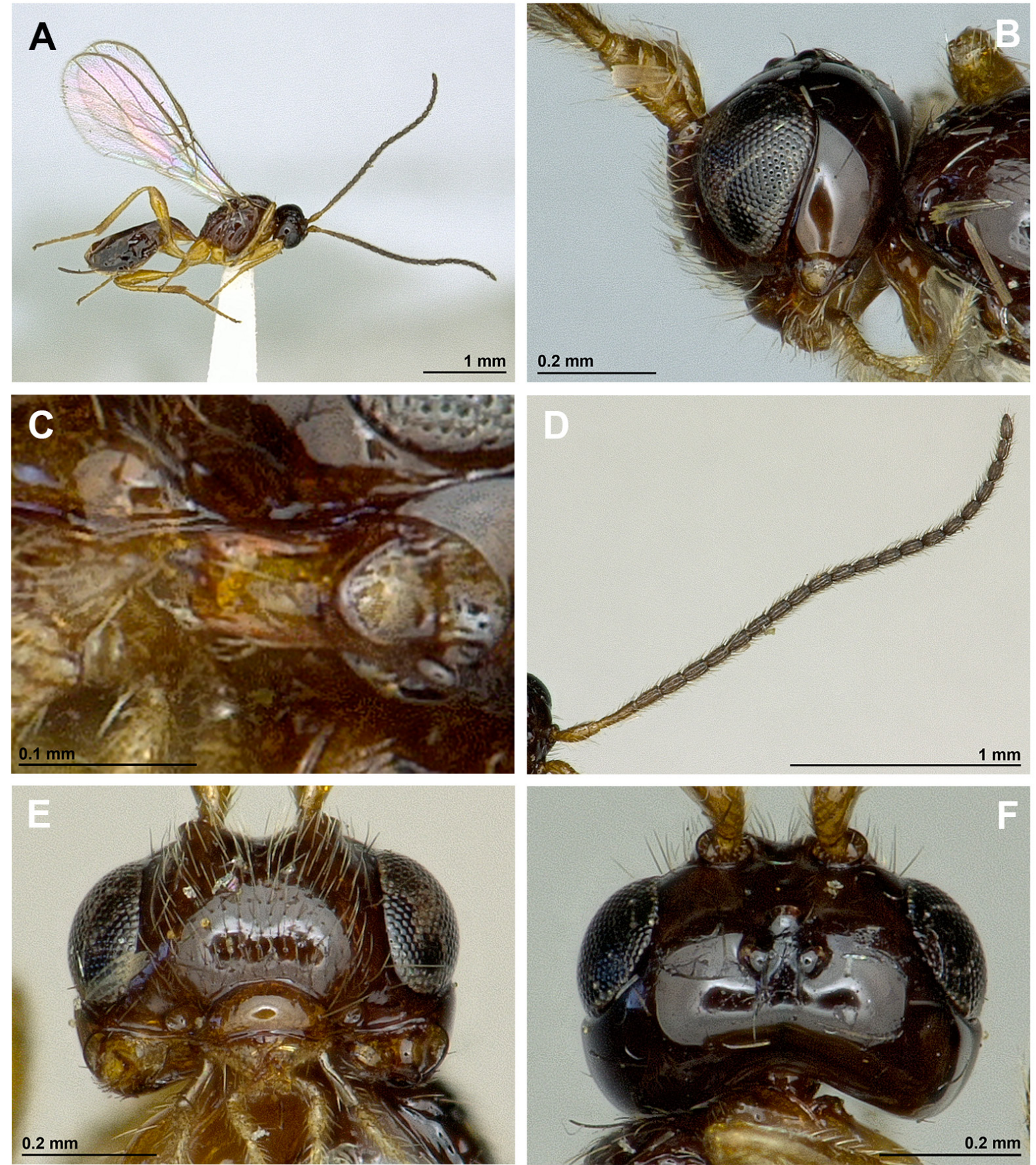

Fig. 4. Synaldis fritzi Peris-Felipo, sp. nov., +. A. Habitus, lateral view. B. Head, lateral view. C. Mandible. D. Antenna. E. Face, front view. F. Head, dorsal view. 
HeAD. In dorsal view, 1.9 times as wide as long, 1.5 times as wide as mesoscutum, smooth, with temple rounded behind eyes. Eye in lateral view 1.6 times as high as wide and 1.1 times as wide as temple medially. POL 1.0 times as long as OD; OOL 2.7 times OD. Face 1.8 times as wide as high, completely covered by numerous setae; inner margins of eyes subparallel. Clypeus 2.5 times as wide as high, slightly concave ventrally. Paraclypeal fovea short, reaching 0.4 times distance between clypeus and eye. Mandible weakly widened towards apex, 1.5 times as long as its maximum width. Upper tooth very small, shorter than lower and middle teeth; middle tooth short, wide basally and pointed apically; lower tooth short, rounded. Antennae 23-segmented, 1.1 times as long as body. Scape 2.5 times as long
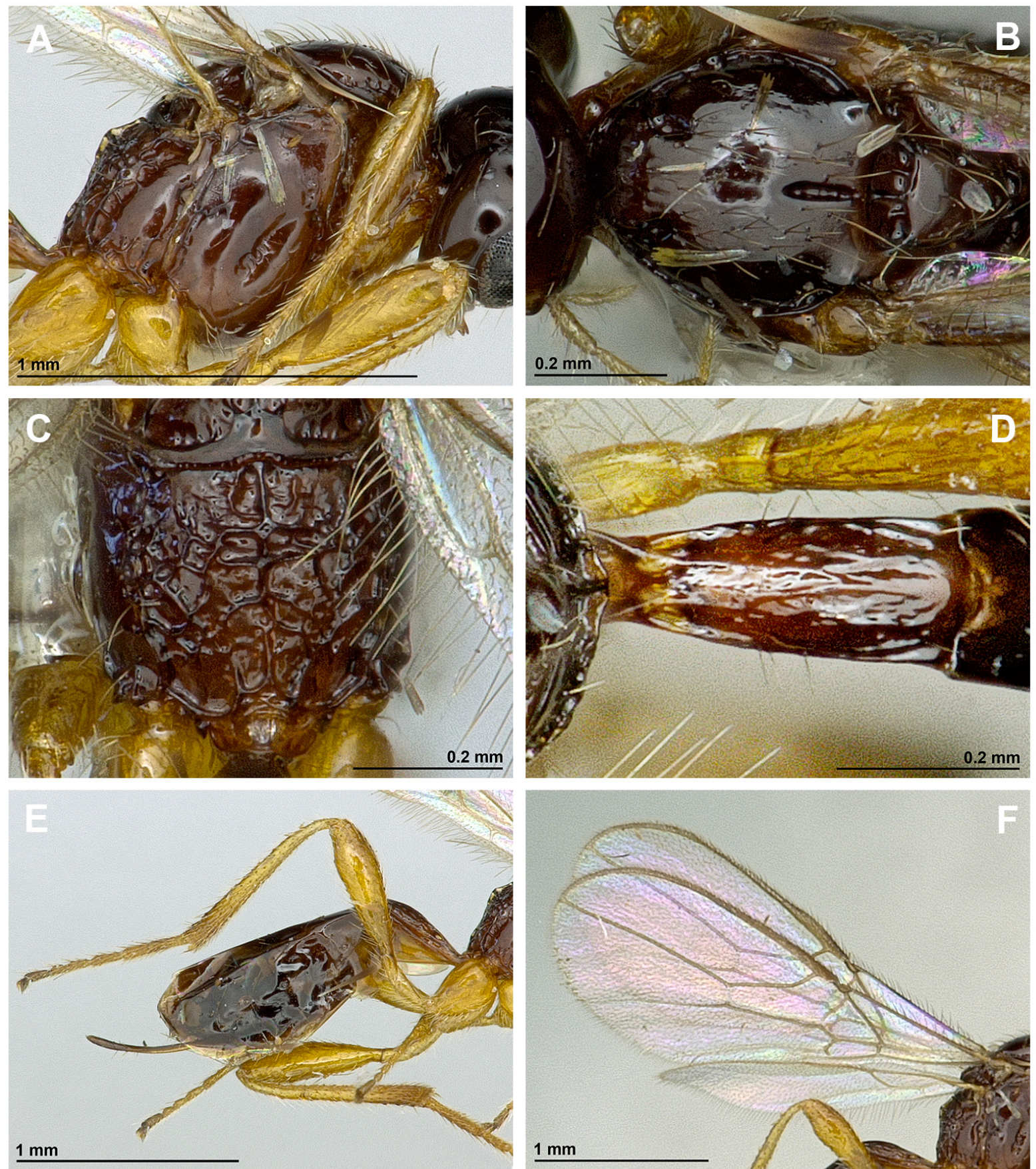

Fig. 5. Synaldis fritzi Peris-Felipo, sp. nov., ․ A. Mesosoma, lateral view. B. Mesonotum, dorsal view. C. Propodeum. D. First metasomal tergite. E. Legs, metasoma and ovipositor, lateral view. F. Fore and hind wings. 
as pedicel. First flagellar segment 3.6 times as long as its apical width, 1.4 times as long as $2^{\text {nd }}$ segment. Second and $3^{\text {rd }}$ flagellar segments 2.0 times, $4^{\text {th }}$ to $8^{\text {th }}$ segments 1.8 times, $9^{\text {th }}$ to $18^{\text {th }}$ segments 2.0 times, $19^{\text {th }}$ and $20^{\text {th }}$ segments 1.8 times, and $21^{\text {st }}$ (apical) segment 2.2 times as long as their maximum width.

Mesosoma. In lateral view 1.3 times as long as high. Mesoscutum (dorsal view) as long as its maximum width, with numerous setae arranged in middle part of mesoscutum. Notauli mainly absent on horizontal surface of mesoscutum. Mesoscutal pit present and elongate. Prescutellar depression smooth, without lateral carinae, twice as long as its maximum width. Precoxal sulcus present, crenulate, not reaching anterior and posterior margins of mesopleuron. Posterior mesopleural furrow smooth. Propodeum sculptured, with complete and distinct median longitudinal carina from its base to apex and with several transverse carinae reaching sides of propodeum. Propodeal spiracles small, its diameter 0.1 times as wide as the distance from spiracle to anterior margin of propodeum.

WiNGs. Length of fore wing 2.8 times its maximum width. Marginal cell ending on apex of wing, 4.2 times as long as its maximum width. Vein SR1 2.8 times as long as vein 3-SR. Vein 3-SR 2.6 times as long as vein r. Vein cu-a distinctly postfurcal. First subdiscal cell closed distally, 2.8 times as long as its maximum width. Hind wing 5.8 times as long as its maximum width.

Legs. Hind femur 3.8 times as long as its maximum width. Hind tibia weakly widened to apex, 8.8 times as long as its maximum subapical width, 1.1 times as long as hind tarsus. First segment of hind tarsus twice as long as second segment.

Metasoma. First tergite weakly widened towards apex, 2.7 times as long as its apical width, weakly striate. Ovipositor as long as first tergite, 0.3 times as long as metasoma, 0.7 times as long as hind femur.

VARIATION. Body $2.4-2.7 \mathrm{~mm}$, fore wing $2.5-2.7 \mathrm{~mm}$, hind wing $1.7-1.8 \mathrm{~mm}$. First flagellar segment 3.6-3.8 times as long as its maximum width. Hind femur 3.8-4.0 times as long as its maximum width.

\section{Male}

Body length $2.4 \mathrm{~mm}$, fore wing $2.5 \mathrm{~mm}$, hind wing $1.8 \mathrm{~mm}$. Antenna 25 -segmented. First flagellar segment 3.4 times as long as its maximum width; second segment 2.7 times, and sixth segment 2.4 times as long as its maximum width. Otherwise similar to female.

Synaldis longiflagellaris Peris-Felipo, sp. nov. urn:lsid:zoobank.org:act:AFA31261-ECAF-4F4D-A628-9E5B5F44CCDA

Figs 6-7

\section{Diagnosis}

This new species is similar to Synaldis novateutoniae sp. nov. and S. segmentata Fischer, 1967. Synaldis longiflagellaris sp. nov. differs from Synaldis novateutoniae sp. nov. in having the first flagellar segment 4.0 times as long as its maximum width (3.5 times in $S$. novateutoniae sp. nov.), second segment 3.23.3 times (2.3 times in $S$. novateutoniae sp. nov.) and middle segments 2.5-2.9 times (1.8-2.0 times in S. novateutoniae sp. nov.) as long as their maximum width, face 1.6 times as long as high (1.8 times in S. novateutoniae sp. nov.), and vein SR1 3.0 times as long as vein 3-SR (2.6 times in S. novateutoniae sp. nov.). Synaldis longiflagellaris sp. nov. differs from $S$. segmentata in having the first flagellar segment 4.0 times as long as its maximum width (3.0 times in $S$. segmentata), second segment 3.2-3.3 times (2.0 times in $S$. segmentata) and middle segments 2.5-2.9 times (1.5 times in $S$. segmentata) as long as their maximum width, mandible 1.6 times as long as wide (1.3 times in $S$. segmentata), marginal cell 4.0 times as long as its maximum width (3.5 times in S. segmentata), and vein SR1 3.0 times as long as vein 3-SR (1.8 times in S. segmentata). 


\section{Etymology}

The name is referring to the long size of the flagellar segments of antennae.

\section{Material examined}

\section{Holotype}

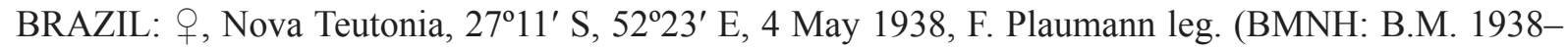
682).
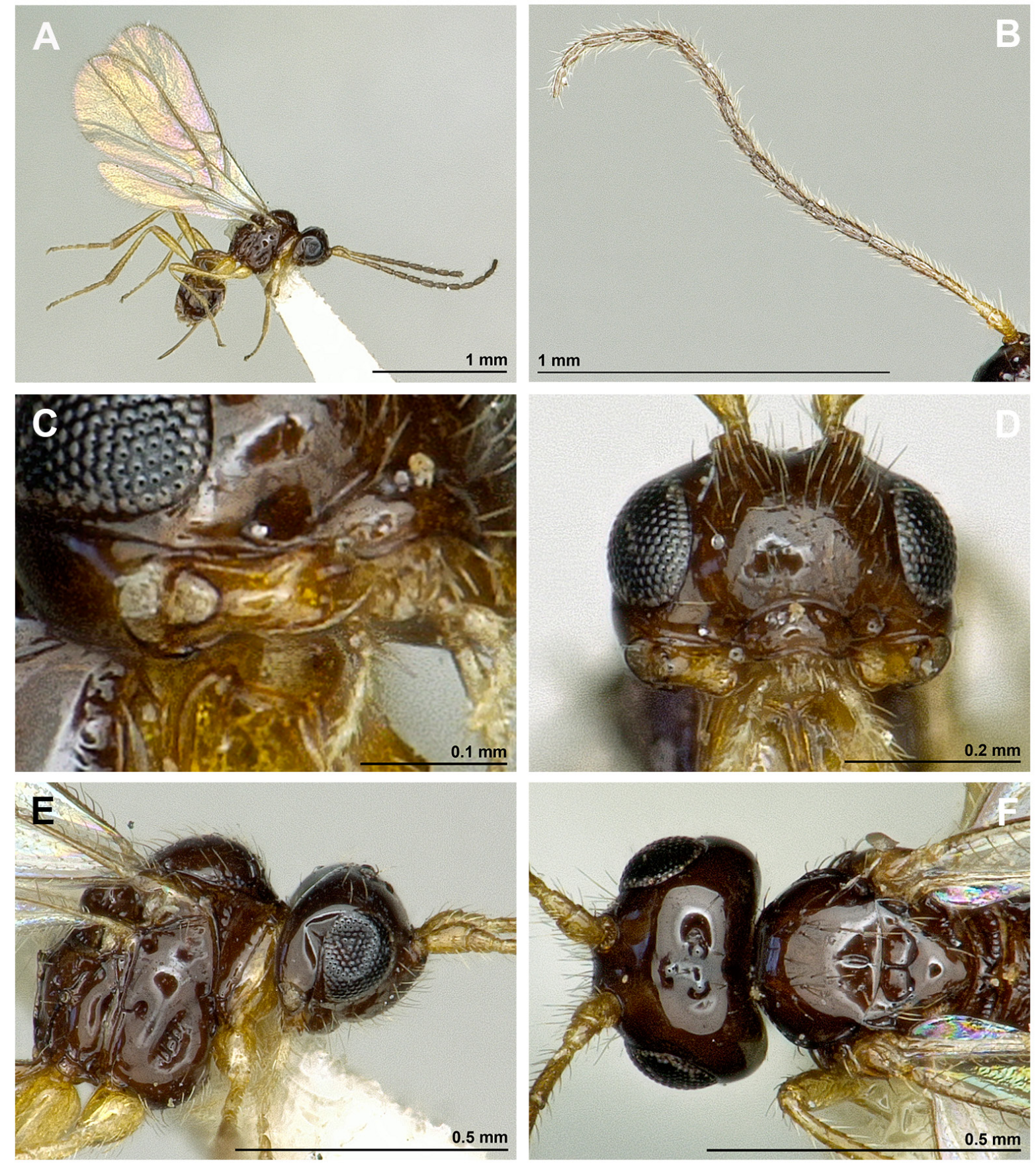

Fig. 6. Synaldis longiflagellaris Peris-Felipo, sp. nov., ㅇ. A. Habitus, lateral view. B. Antenna. C. Mandible. D. Face, front view. E. Head and mesosoma, lateral view. F. Head and mesonotum, dorsal view. 


\section{Paratypes}

BRAZIL: 3 우, 4 ○ึ, same locality as holotype, but 14-15 and 18 Mar. 1937 (B.M. 1937-424), 20, 24 and 30 Apr. 1938 (B.M. 1938-682) and 4 Jun. 1952 (B.M. 1957-341) (BMNH, ZISP).

\section{Description}

Female (holotype)

Length. Body $1.6 \mathrm{~mm}$, fore wing $1.8 \mathrm{~mm}$, hind wing $1.3 \mathrm{~mm}$.

Colour. Body, pterostigma and flagellar segments of antenna brown; legs, scape and pedicel of antenna brownish yellow. Lower part of pronotal side and propleuron yellow. Wings hyaline.

HEAD. In dorsal view, 1.8 times as wide as long, 1.5 times as wide as mesoscutum, smooth, with temple rounded behind eyes. Eye in lateral view 1.3 times as high as wide and 1.4 times as wide as temple medially. POL 1.1 times as long as OD; OOL 2.5 times OD. Face 1.6 times as wide as high, completely covered by numerous setae; inner margins of eyes subparallel. Clypeus 2.3 times as wide as high, slightly concave ventrally. Paraclypeal fovea reaching half of distance between clypeus and eye. Mandible weakly widened towards apex, 1.6 times as long as its maximum width. Upper tooth small, slightly shorter than middle tooth; middle tooth short, wide basally and pointed apically; lower tooth short, wide, rounded. Antenna 18-segmented, 1.1 times as long as body. Scape 1.5 times as long as pedicel. First flagellar segment 4.0 times as long as its apical width, about as long as second segment.
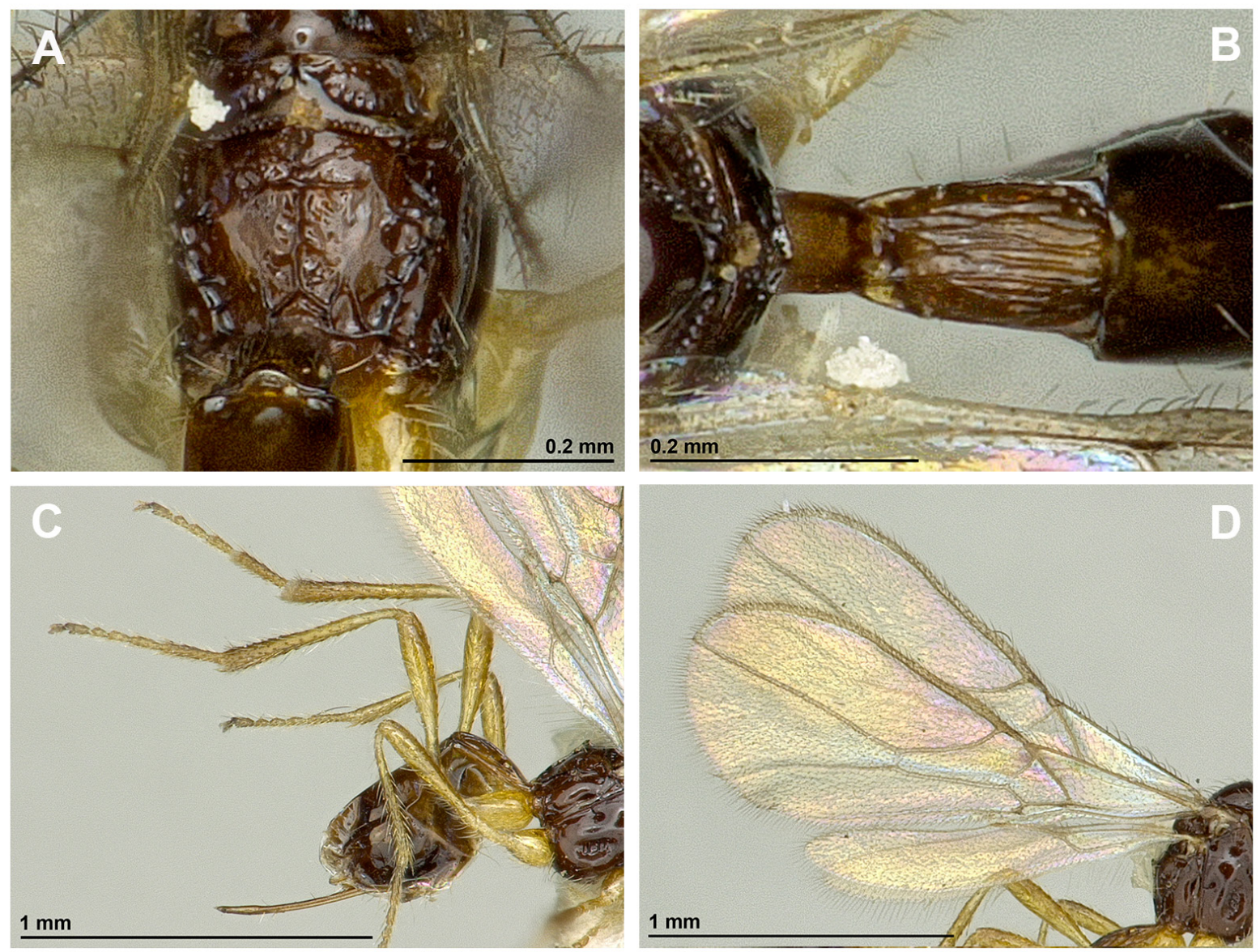

Fig. 7. Synaldis longiflagellaris Peris-Felipo, sp. nov., +. A. Propodeum. B. First metasomal tergite. C. Legs, metasoma and ovipositor, lateral view. D. Fore and hind wings. 
Second flagellar segment 3.2 times as long as its maximum width, third to sixth segments 2.9 times, seventh to $13^{\text {th }}$ segments 2.5 times, and $14^{\text {th }}$ to $16^{\text {th }}$ (apical) segments 2.9 times as long as their width.

Mesosoma. In lateral view 1.1 times as long as high. Mesoscutum (dorsal view) about as long as its maximum width, with sparse double setae arranged along notaulus line. Notauli mainly absent on horizontal surface of mesoscutum. Mesoscutal pit present and elongate. Prescutellar depression smooth, without lateral carinae. Precoxal sulcus present, crenulate, not reaching anterior and posterior margins of mesopleuron. Posterior mesopleural furrow smooth. Propodeum sculptured, with complete and distinct median longitudinal carina from its base to apex, with long transverse carinae not reaching sides of propodeum. Propodeal spiracles small, its diameter about 0.1 times as large as distance from spiracle to anterior margin of propodeum.

Wings. Length of fore wing 3.0 times its maximum width. Marginal cell ending on apex of wing, 4.0 times as long as its maximum width. Vein SR1 3.0 times as long as vein 3-SR. Vein 3-SR 2.8 times as long as vein $\mathrm{r}$. Vein cu-a distinctly postfurcal. First subdiscal cell closed distally, 3.8 times as long as its maximum width. Hind wing 6.5 times as long as its maximum width.

Legs. Hind femur 4.6 times as long as its maximum width. Hind tibia weakly widened to apex, 8.2 times as long as its maximum subapical width, 1.1 times as long as hind tarsus. First segment of hind tarsus 1.7 times as long as second segment.

Metasoma. First tergite weakly widened towards apex, 2.1 times as long as its apical width, entirely striate. Ovipositor 1.6 times as long as first tergite, 0.7 times as long as metasoma, 1.1 times as long as hind femur.

VARIATION. Body 1.6-1.8 mm; fore wing 2.0-2.2 mm; hind wing 1.3-1.5 mm. Hind femur 4.4-4.5 times as long as its maximum width.

\section{Male}

Body length 1.5-1.7 mm, fore wing 1.4-1.6 mm, hind wing 1.2-1.3 mm. Antenna 21-22-segmented. Middle flagellar segments (seventh to 13th) 2.9 times as long as their maximum width. Otherwise similar to female.

Synaldis magnioculis Peris-Felipo, sp. nov. urn:lsid:zoobank.org:act:DCD0FC73-C2FB-4114-80DC-0FDCEDE20FB2

Figs 8-9

\section{Diagnosis}

This new species is similar to Synaldis fritzi sp. nov.; differences between both species are described under the latter species.

\section{Etymology}

The specific epithet is derived from the Latin "magnus", meaning "big", and "oculus", meaning "eye" because of the large eye in lateral view.

\section{Material examined}

\section{Holotype}

BRAZIL: + , Nova Teutonia, $27^{\circ} 11^{\prime}$ S, 52²3' E, 30 Apr. 1938, F. Plaumann leg. (BMNH: B.M. 1938682). 


\section{Paratypes}

BRAZIL: 1 , , same data as holotype (BMNH).

\section{Description}

Female (holotype)

LENGTH. Body $1.7 \mathrm{~mm}$, fore wing $1.8 \mathrm{~mm}$, hind wing $1.4 \mathrm{~mm}$.
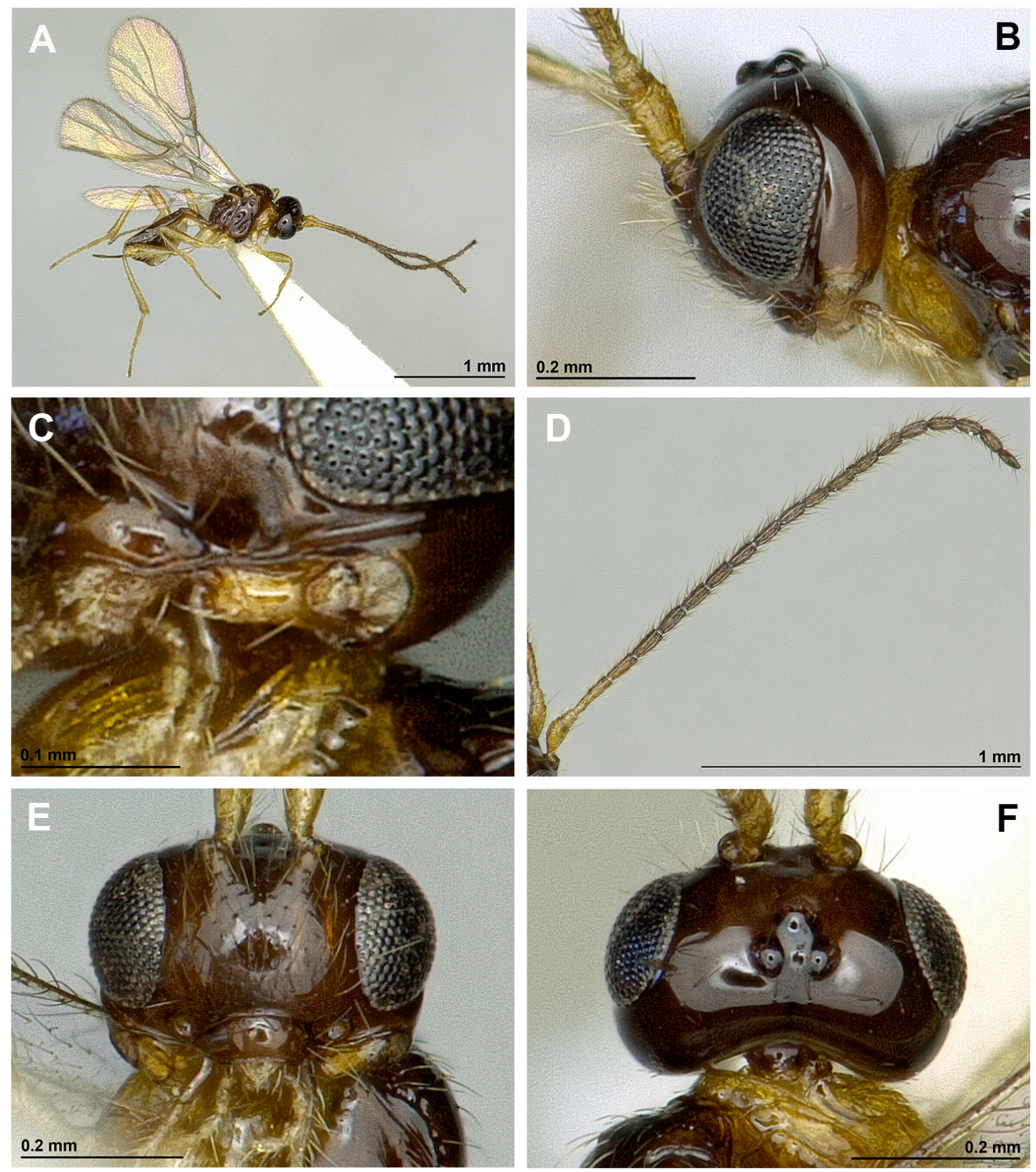

Fig. 8. Synaldis magnioculis Peris-Felipo, sp. nov., ․ . A. Habitus, lateral view. B. Head, lateral view. C. Mandible. D. Antenna. E. Face, front view. F. Head, dorsal view. 
CoLour. Body, pterostigma and flagellar segments of antenna brown, scape and pedicel of antenna brownish yellow. Lower part of pronotal side and propleuron yellow. Legs yellow. First metasomal tergite similar colour to second and third tergites. Wings hyaline.

HEAD. In dorsal view, 1.7 times as wide as long, 1.4 times as wide as mesoscutum, smooth, with temple rounded behind eyes. Eye in lateral view 1.5 times as high as wide and 1.7 times as wide as temple medially. POL 0.9 times as long as OD; OOL 2.4 times OD. Face 1.2 times as wide as high, with numerous setae; inner margins of eyes subparallel. Clypeus 2.5 times as wide as high, slightly concave
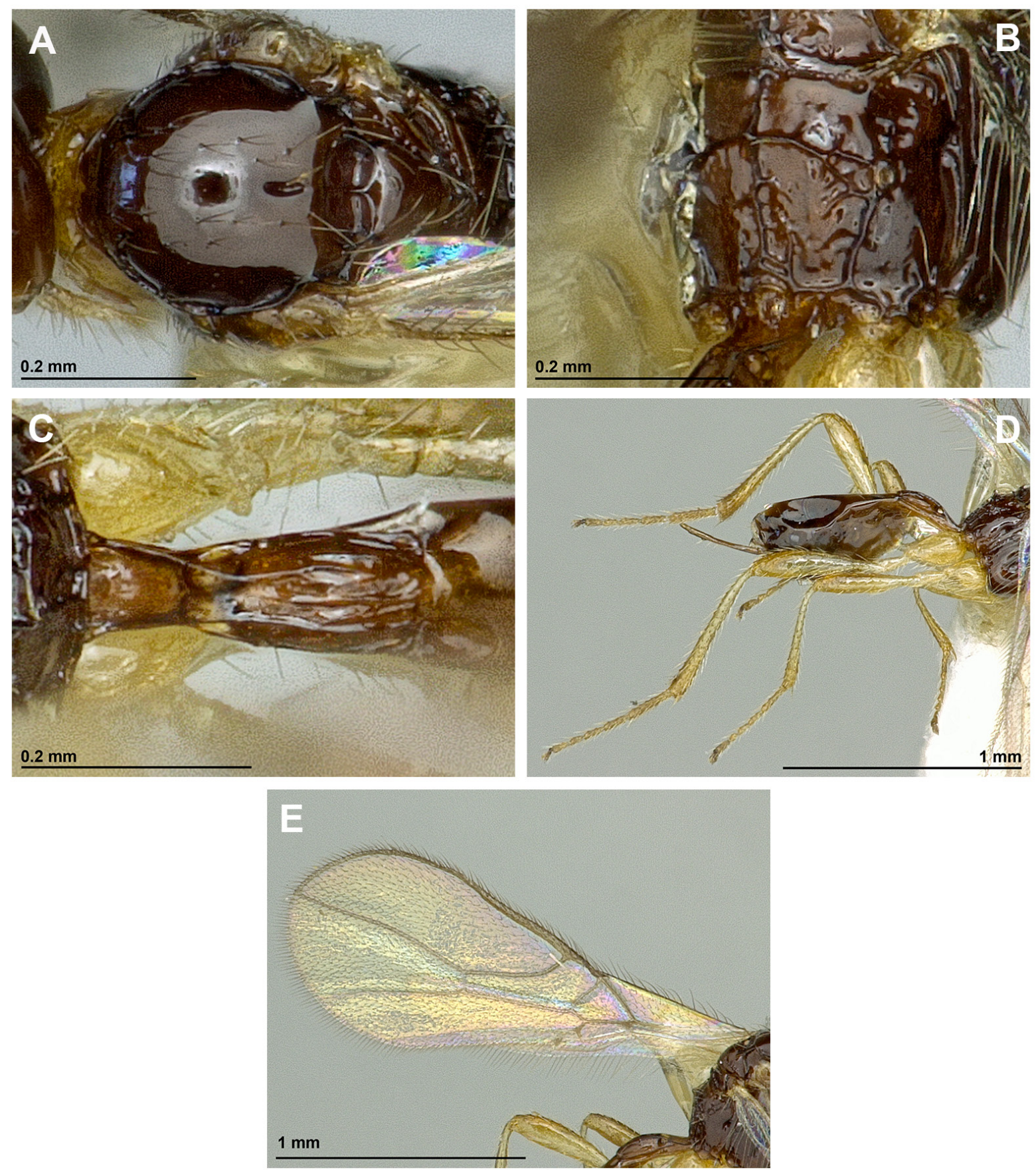

Fig. 9. Synaldis magnioculis Peris-Felipo, sp. nov., ․ A. Mesonotum, dorsal view. B. Propodeum. C. First metasomal tergite. D. Legs, metasoma and ovipositor, lateral view. E. Fore wing. 
ventrally. Paraclypeal fovea reaching half distance between clypeus and eye. Mandible not widened towards apex, 1.9 times as long as its maximum width. Upper tooth very small, shorter than middle tooth; middle tooth small, wide basally and pointed apically; lower tooth short, as long as upper tooth, rounded. Antennae 20-segmented, 1.1 times as long as body. Scape 2.0 times as long as pedicel. First flagellar segment 3.5 times as long as its apical width, 1.4 times as long as $2^{\text {nd }}$ segment. Second flagellar segment 2.5 times, $3^{\text {rd }}$ to $5^{\text {th }}$ segments 2.1 times, $6^{\text {th }}$ to $8^{\text {th }}$ segments 2.5 times, $9^{\text {th }}$ to $17^{\text {th }}$ segments 2.2 times, and $18^{\text {th }}$ (apical) segment 2.4 times as long as their maximum width.

Mesosoma. In lateral view 1.2 times as long as high. Mesoscutum (dorsal view) as long as its maximum width, with sparse single setae arranged along notaulus line. Notauli mainly absent on horizontal surface of mesoscutum. Mesoscutal pit present and elongate. Prescutellar depression smooth, without lateral carinae. Precoxal sulcus present, crenulate, not reaching anterior and posterior margins of mesopleuron. Posterior mesopleural furrow smooth. Propodeum sculptured, with complete and distinct median longitudinal carina from its base to apex, with one transverse carina reaching both sides of propodeum. Propodeal spiracles relatively small, its diameter 0.2 times as wide as the distance from spiracle to anterior margin of propodeum.

WINGS. Length of fore wing 2.7 times its maximum width. Marginal cell ending on apex of wing, 3.8 times as long as its maximum width. Vein SR1 2.6 times as long as vein 3-SR. Vein 3-SR 1.8 times as long as vein $\mathrm{r}$. Vein cu-a distinctly postfurcal. First subdiscal cell closed distally, 4.0 times as long as its maximum width. Hind wing 5.7 times as long as its maximum width.

LEGS. Hind femur 3.9 times as long as its maximum width. Hind tibia weakly widened to apex, 9.6 times as long as its maximum subapical width, as long as hind tarsus. First segment of hind tarsus 1.7 times as long as second segment.

Metasoma. First tergite weakly widened towards apex, 2.7 times as long as its apical width, striate. Ovipositor 1.2 times as long as first tergite, 0.4 times as long as metasoma, 0.8 times as long as hind femur.

VARIATION. Hind femur 3.8-4.0 times as long as its maximum width.

Male

Unknown.

Synaldis novateutoniae Peris-Felipo, sp. nov. urn:lsid:zoobank.org:act:A3CE6DFF-6A46-4242-9E15-6125CFB452FF

Figs 10-11

\section{Diagnosis}

This new species is similar to Synaldis longiflagellaris sp. nov. and S. segmentata Fischer, 1967. Differences between $S$. novateutoniae sp. nov. and S. longiflagellaris sp. nov. are described after the description of $S$. longiflagellaris sp. nov. Synaldis novateutoniae sp. nov. differs from S. segmentata in having the first flagellar segment 3.5 times as long as its maximum width (3.0 times in $S$. segmentata), second segment 2.3 times (2.0 times in $S$. segmentata) and middle segments 1.8-2.0 times (1.5 times in $S$. segmentata) as long as their maximum width; mandible 1.8 times as long as wide (1.3 times in S. segmentata), marginal cell 4.0 times as long as its maximum width (3.5 times in $S$. segmentata), and vein SR1 2.6 times as long as vein 3-SR (1.8 times in S. segmentata). 


\section{Etymology}

The specific epithet refers to Teutônia ("Nova Teutonia"), the type locality of the species.

\section{Material examined}

\section{Holotype}

BRAZIL: ㅇ, Nova Teutonia, 271' S, 52²3' E, 27 Apr. 1938, F. Plaumann leg. (BMNH: B.M. 1938682).
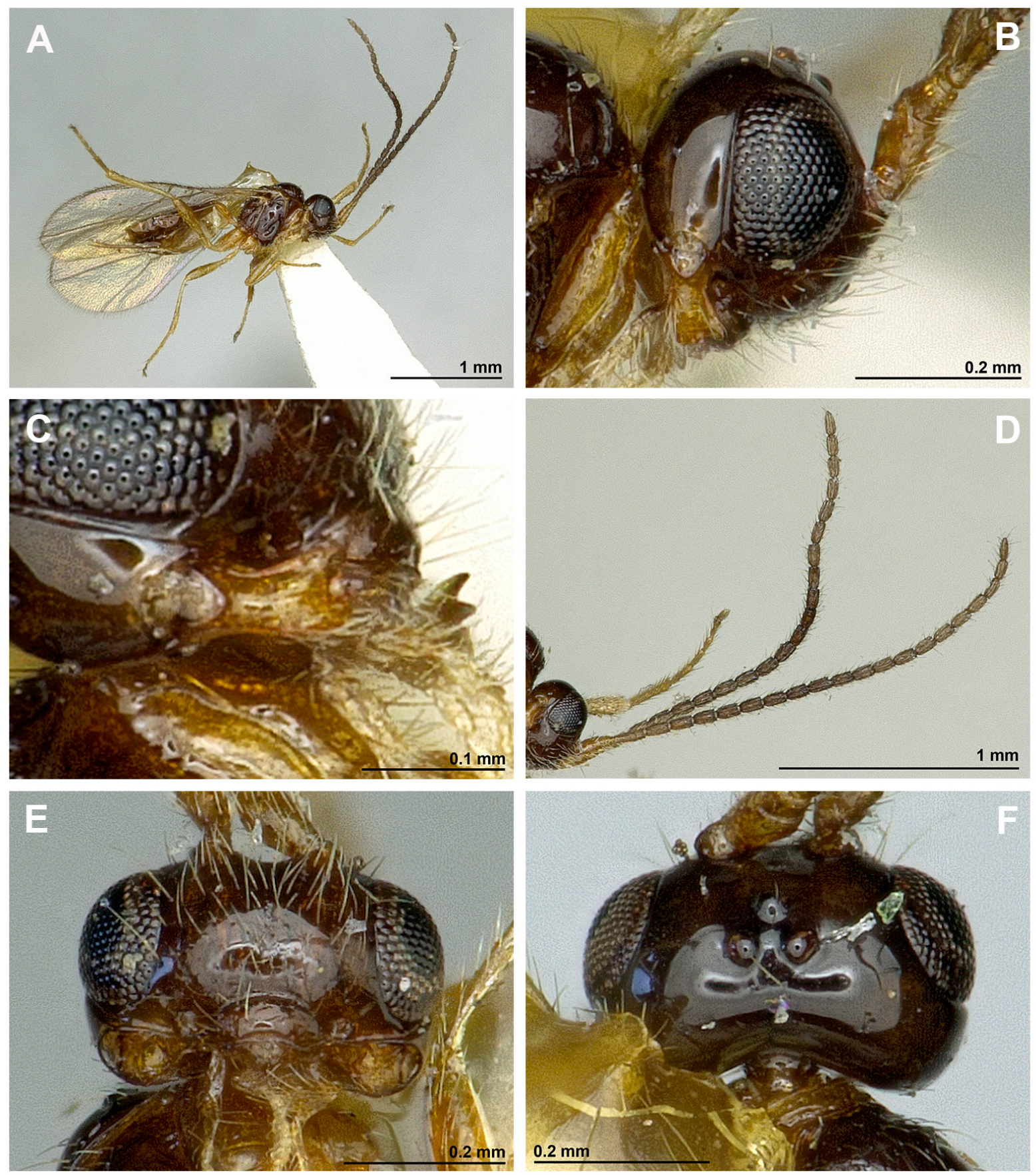

Fig. 10. Synaldis novateutoniae Peris-Felipo, sp. nov.,, . A. Habitus, lateral view. B. Head, lateral view. C. Mandible. D. Antenna. E. Face, front view. F. Head, dorsal view. 


\section{Paratypes}

BRAZIL: 3 우, 2 $ふ$ , same locality as holotype, but 8 Aug., 7 Sep. 1935 and 8 Sep. 1937 (1937-656), and 9 May 1952 (1957-341) (BMNH, ZISP).

\section{Description}

Female (holotype)

Length. Body $1.9 \mathrm{~mm}$, fore wing $2.1 \mathrm{~mm}$, hind wing $1.6 \mathrm{~mm}$.

Colour. Body, pterostigma and flagellar segments of antenna brown; legs, scape and pedicel of antenna brownish yellow. Lower part of pronotal side and propleuron yellow. Wings hyaline.

HEAD. In dorsal view, 1.9 times as wide as long, 1.4 times as wide as mesoscutum, smooth, with temple rounded behind eyes. Eye in lateral view 1.5 times as high as wide and 1.4 times as wide as temple medially. POL 1.0 times as long as OD; OOL 2.7 times OD. Face 1.8 times as wide as high, completely covered by numerous setae; inner margins of eyes subparallel. Clypeus 2.5 times as wide as high, slightly concave ventrally. Paraclypeal fovea reaching half distance between clypeus and eye. Mandible weakly widened towards apex, 1.8 times as long as its maximum width. Upper tooth small, shorter than lower teeth; middle tooth small, slightly longer than upper tooth, wide basally and pointed apically; lower tooth short, wide, rounded. Antennae 22-segmented, 1.1 times as long as body. Scape 1.8 times as long as pedicel. First flagellar segment 3.5 times as long as its apical width, 1.3 times as long as second segment. Second flagellar segment 2.3 times, third to sixth segments 1.8 times; seventh to $17^{\text {th }}$ segments about 2.0 times, $18^{\text {th }}$ and $19^{\text {th }}$ segments 2.2 times, and $20^{\text {th }}$ (apical) segment 2.8 times as long as their maximum width.

Mesosoma. In lateral view 1.1 times as long as high. Mesoscutum (dorsal view) as long as its maximum width, with sparse single setae arranged along notaulus line. Notauli mainly absent on horizontal surface of mesoscutum. Mesoscutal pit present and elongate. Prescutellar depression smooth, without lateral carinae. Precoxal sulcus present, not reaching anterior and posterior margins of mesopleuron. Posterior mesopleural furrow smooth. Propodeum sculptured, with complete and distinct median longitudinal carina from its base to apex, with very short transverse carinae far from reaching sides of propodeum. Propodeal spiracles small, its diameter 0.4 times as wide as the distance from spiracle to anterior margin of propodeum.

WiNGS. Length of fore wing 2.8 times its maximum width. Marginal cell ending on apex of wing, 4.0 times as long as its maximum width. Vein SR1 2.6 times as long as vein 3-SR. Vein 3-SR 3.4 times as long as vein $\mathrm{r}$. Vein cu-a distinctly postfurcal. First subdiscal cell closed distally, 4.0 times as long as its maximum width. Hind wing 5.7 times as long as its maximum width.

Legs. Hind femur 4.4 times as long as its maximum width. Hind tibia weakly widened to apex, 7.5 times as long as its maximum subapical width, as long as hind tarsus. First segment of hind tarsus 1.9 times as long as second segment.

Metasoma. First tergite weakly widened towards apex, 2.2 times as long as its apical width, weakly striate. Ovipositor 1.7 times as long as first tergite, 0.5 times as long as metasoma, 1.1 times as long as hind femur.

VARIATION. Body 1.8-2.0 mm, fore wing 2.0-2.2 mm, hind wing 1.3-1.5 mm. Antenna 19-22-segmented. Middle flagellar segments 1.8-2.0 times as long as their maximum width. First metasomal tergite 2.02.2 times as long as its apical width. 


\section{Male}

Body length 1.7-1.8 mm, fore wing 1.8-2.0 mm, hind wing 1.3-1.5 mm. Antenna 25-26-segmented. Otherwise similar to female.

\section{Key to the Nearctic and Neotropical species of Synaldis}

1. Propodeum smooth, without or with short transverse carinae ending far from sides (Figs 7A, 11C) ...2

- Propodeum sculptured, always with transverse carinae reaching its lateral sides (Figs 3C, 5C, 9B) ...9

2. Prescutellar pit absent [Antenna 20-segmented. Body length $1.7 \mathrm{~mm}$. USA]

S. cabinica Fischer, 1967

- Prescutellar pit present .3

3. Eye in lateral view $0.8-1.0$ times as long as temple medially ..............................

- Eye in lateral view $1.3-1.5$ times as long as temple medially .................................

4. First flagellar segment 1.6 times, second segment 1.4 times, and sixth segment 1.4 times as long as their maximum width. Mandible 1.3 times as long as its maximum width (Fig. 12A) [Antenna 18-segmented. Body length $1.7 \mathrm{~mm}$. USA] ...................S. acutidens Fischer, 1967

- First flagellar segment 2.6-3.3 times, second segment 2.1-2.4 times, and sixth segment 1.9 times as long as their maximum width. Mandible as long as its maximum width (Fig. 12B) ........5

5. First flagellar segment 2.6 times as long as its maximum width. Marginal cell 4.2 times as long as its maximum width. Vein SR1 2.9 times as long as 3-SR. Head in dorsal view 1.5 times as long as its median length. Clypeus 2.2 times as long as its maximum width. [Antenna 19-segmented. Body length 1.4 mm. USA] .......................... S. pygmaea Viereck, 1917

- First flagellar segment 3.3 times as long as its maximum width. Marginal cell 4.7 times as long as its maximum width. Vein SR1 3.8 times as long as 3-SR. Head in dorsal view 1.8 times as long as its median length. Clypeus 2.7 times as long as its maximum width. [Antenna 16-segmented (apical segments broken). Body length $1.6 \mathrm{~mm}$. USA] ...........S. blantoni Fischer, 1967

6. Hind femur 4.0 times as long as its maximum width. First metasomal tergite 1.6 times as long as its apical width. Face 2.2-2.4 times as wide as high (Fig. 12C). Vein SR1 3.6 times as long as vein 3-SR. [Antenna 12-segmented (apical segments broken). Body length $1.9 \mathrm{~mm}$. USA] ...S. rotundidens Fischer, 1967

- Hind femur 4.4-4.6 times as long as its maximum width. First metasomal tergite 2.0-2.2 times as long as its apical width. Face 1.6-1.8 times as wide as high (Fig. 12D). Vein SR1 1.8-3.0 times as long as vein 3 -SR

7. Mandible 1.3 times as long as its maximum width. First flagellar segment 3.0 times and sixth segment 1.5 times as long as their maximum width. Marginal cell 3.5 times as long as its maximum width. Vein SR1 1.8 times as long as vein 3-SR [Antenna 24-segmented. Body length $2.4 \mathrm{~mm}$. USA] ......

S. segmentata Fischer, 1967

- Mandible 1.6-1.8 times as long as its maximum width (Figs 6C, 10C). First flagellar segment 3.5-4.0 times and sixth segment 1.8-2.9 times as long as their maximum width (Figs 6B, 10D). Marginal cell 4.0 times as long as its maximum width (Figs 7D, 11F). Vein SR1 2.6-3.0 times as long as vein 3-SR

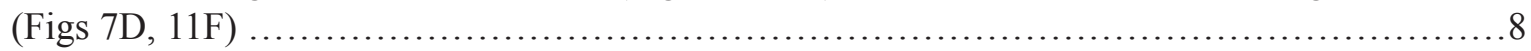

8. First flagellar segment 3.5 times, second segment 2.3 times and middle segments $1.8-2.0$ times as long as their maximum width. First flagellar segment 1.3 times as long as second segment. Scape 1.8 times as long as pedicel (Fig. 10B). Vein SR1 2.6 times as long as vein 3-SR (Fig. 11F) [Antenna 19-26-segmented. Body length 1.8-2.0 mm. Brazil] .....S. novateutoniae Peris-Felipo, sp. nov.

- First flagellar segment 4.0 times, second segment 3.2-3.3 times and middle segments 2.5-2.9 times as long as their maximum width. First flagellar segment about as long as second segment. Scape 
1.5 times as long as pedicel (Fig. 6E). Vein SR1 3.0 times as long as vein 3-SR (Fig. 7D) [Antenna 18-21-segmented. Body length 1.5-1.7 mm. Brazil] ..........S. longiflagellaris Peris-Felipo, sp. nov.

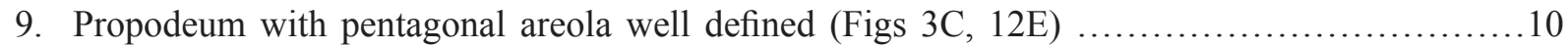

- Propodeum without pentagonal areola (Figs 5C, 13A) .................................... 11
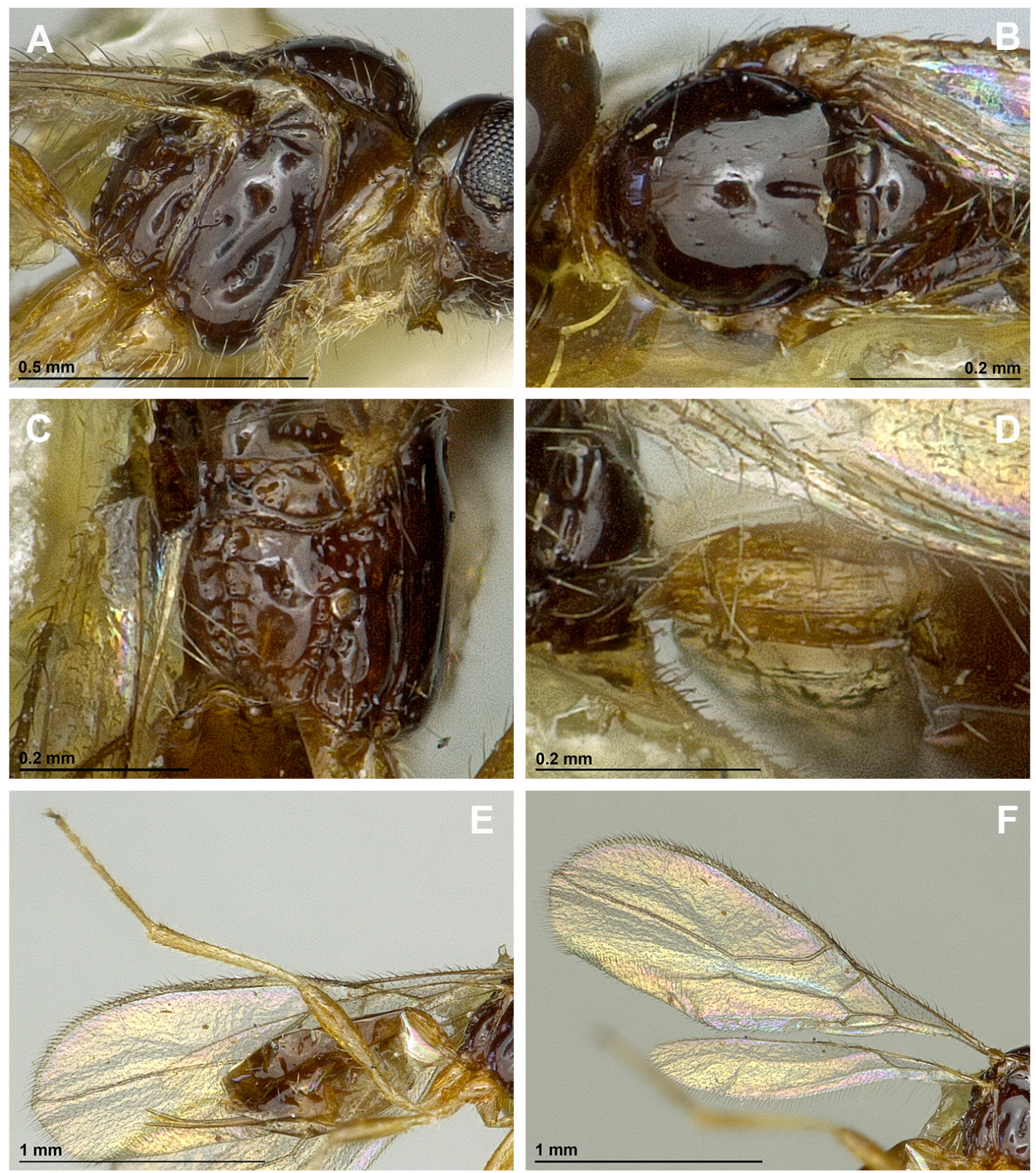

Fig. 11. Synaldis novateutoniae Peris-Felipo, sp. nov., + . A. Mesosoma, lateral view. B. Mesonotum, dorsal view. C. Propodeum. D. First metasomal tergite. E. Legs, metasoma and ovipositor, lateral view. F. Fore and hind wings. 
10. Prescutellar pit absent. Mandible 1.5 times as long as its maximum width. First metasomal tergite 2.1 times as long as its apical width [Antenna 25-segmented. Body length $2.6 \mathrm{~mm}$. USA] .

S. glabrifovea Fischer, 1967

- Prescutellar pit present (Fig. 3B). Mandible 1.8 times as long as its maximum width (Fig. 2C). First metasomal tergite 2.4 times as long as its apical width (Fig. 2D) [Antenna 20-21-segmented. Body length 1.5-1.7 mm. Brazil] ........S. brasiliense Peris-Felipo, sp. nov.

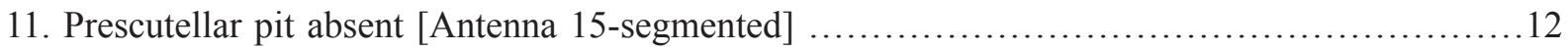

- Prescutellar pit present .................................................................
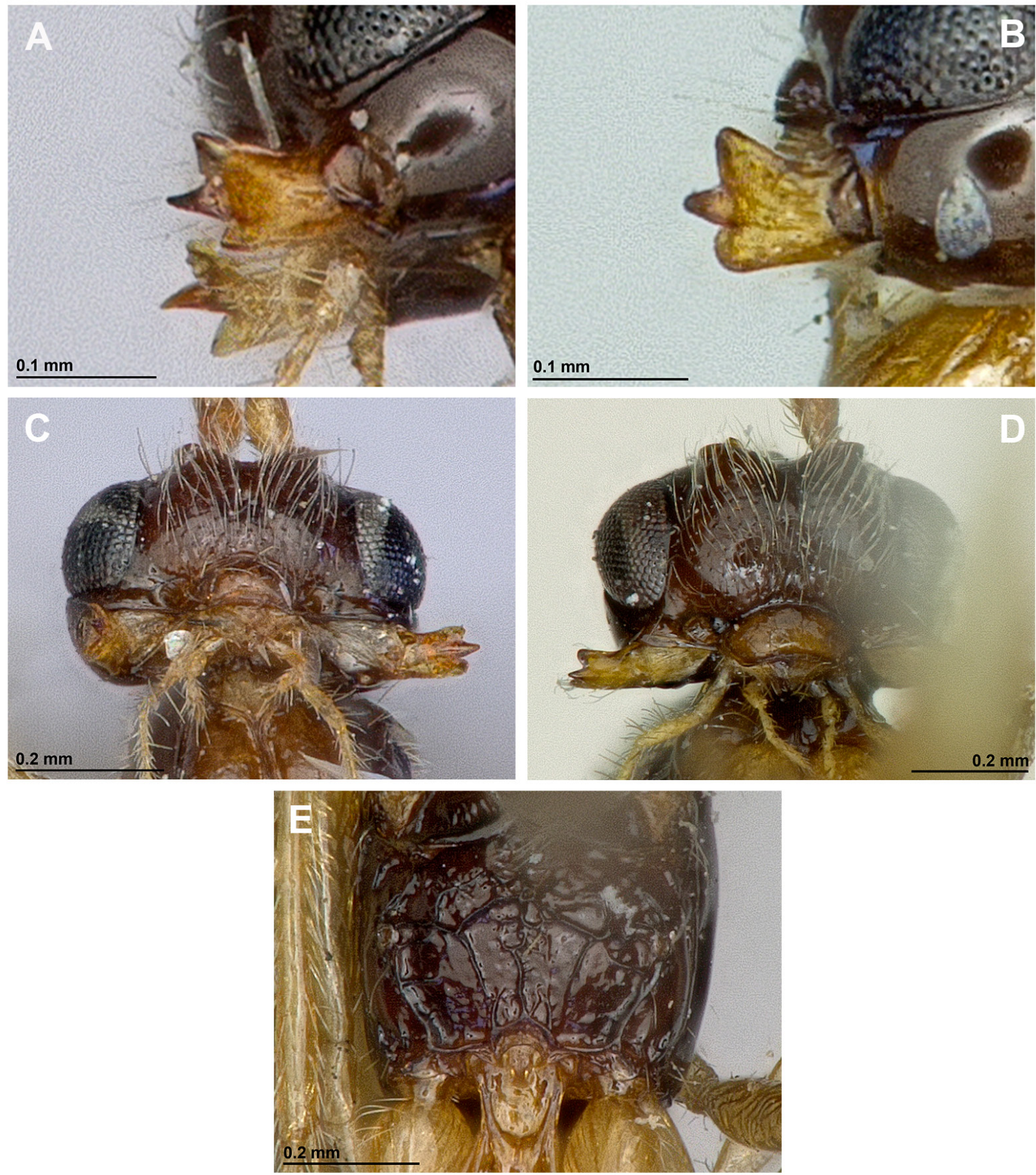

Fig. 12. A. Mandible of Synaldis acutidens Fischer, 1967. B. Mandible of S. pygmaea Viereck, 1917. C. Face of S. rotundidens Fischer, 1967, front view. D. Face of S. segmentata Fischer, 1967, front view.

E. Propodeum of S. glabrifovea Fischer, 1967, dorsal view. 
12. First flagellar segment 2.6 times as long as its maximum width. Apical flagellar segment 2.1 times as long as its maximum width. Face 1.6 times as wide as high. Clypeus 3.2 times as long as high. Mandible 1.4 times as long as its maximum width. [Antenna 15-segmented. Body length $1.6 \mathrm{~mm}$. USA] ......................................S. ulmicola Ashmead, 1889 stat rev.
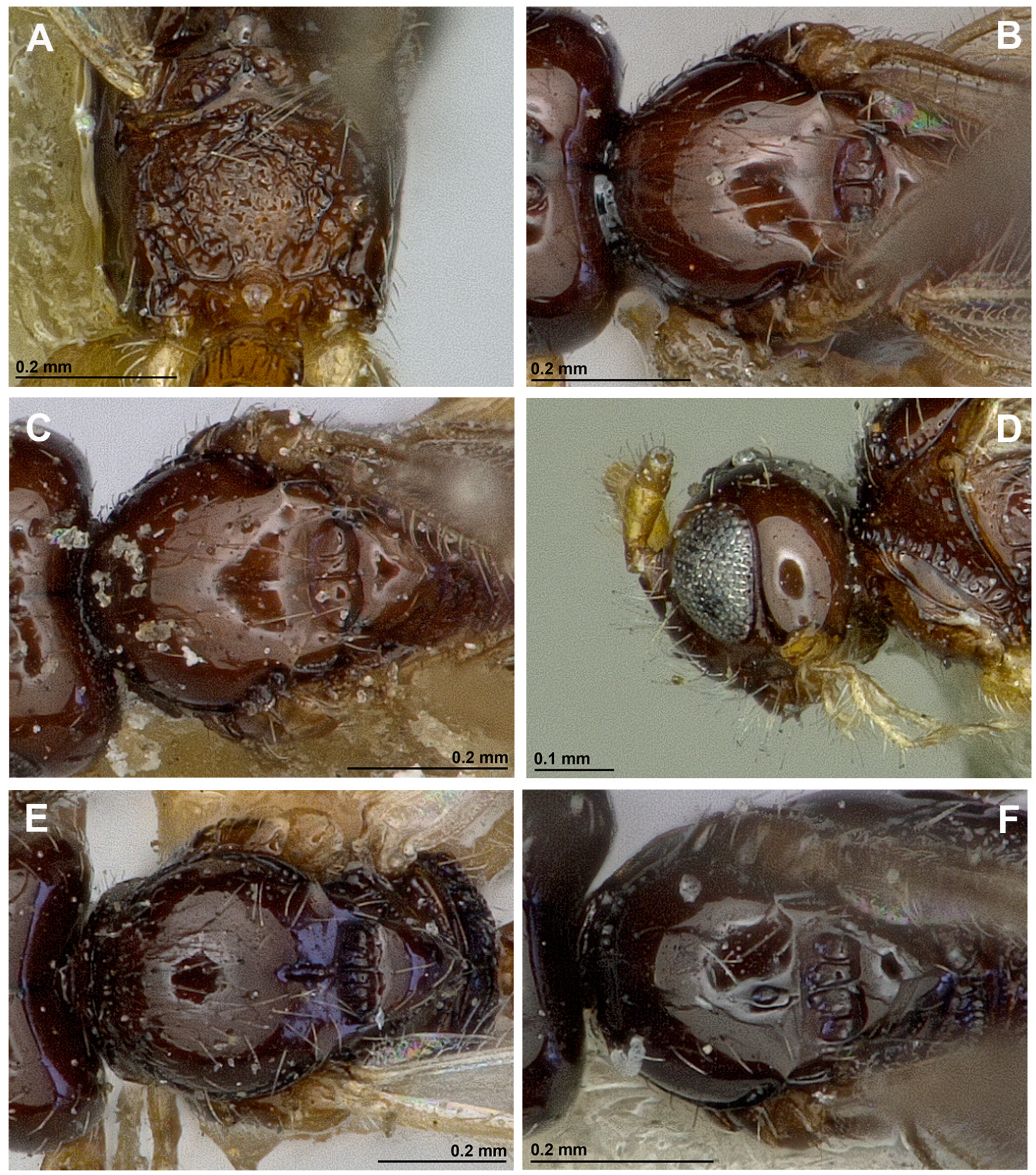

Fig. 13. A. Propodeum of Synaldis ulmicola Ashmead, 1889, dorsal view. B. Mesonotum of S. exitiosiae Fischer, 1967, dorsal view. C. Mesonotum of S. painteri Fischer, 1967, dorsal view. D. Head of S. quinnipiacorum Viereck, 1917, lateral view. E. Mesonotum of S. incisa Gahan, 1912, dorsal view. F. Mesonotum of $S$. alfalfae Fischer, 1967, dorsal view. 
- First flagellar segment 1.8-2.2 times as long as its maximum width. Apical flagellar segment 1.8 times as long as its maximum width. Face 1.9-2.0 times as wide as high. Clypeus 2.8 times as long as high. Mandible 1.0-1.2 times as long as its maximum width .13

13. Eye in lateral view 1.3 times as long as its temple medially. First flagellar segment 1.8 times as long as its maximum width. Scape of antenna 2.3 times as long as pedicel. Prescutellar depression as long as its maximum width (Fig. 13B). Marginal cell 4.1 times as long as its maximum width [Antenna 15-segmented. Body length 1.7 mm. USA] ..................S. exitiosae Fischer, 1967

- Eye in lateral view 1.6 times as long as its temple medially. First flagellar segment 2.2 times as long as its maximum width. Scape of antenna 1.8 times as long as pedicel. Prescutellar depression 1.5 times as long as its maximum width (Fig. 13C). Marginal cell 4.5 times as long as its maximum width [Antenna 15-segmented. Body length $1.8 \mathrm{~mm}$. USA]

S. painteri Fischer, 1967

14. Eye in lateral view $0.7-0.8$ times as long as temple medially (Fig. 13D) ...................... 15

- Eye in lateral view 1.0-1.7 times as long as temple medially (Fig. 4B) .......................17

15. Precoxal sulcus reaching anterior margin of mesopleuron. Hind femur 3.5 times as long as its maximum width [Antenna broken. Body length $1.7 \mathrm{~mm}$. USA] ...S. quinnipiacorum Viereck, 1917

- Precoxal sulcus not reaching anterior margin of mesopleuron. Hind femur 4.0 times as long as its

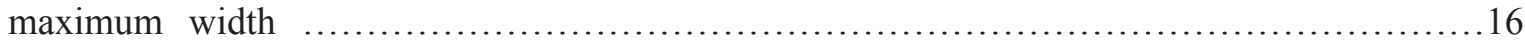

16. First metasomal tergite 1.3 times as long as its apical width. Second flagellar segment 1.6 times and sixth segment 1.1 times as long as their maximum width. Mandible as long as its maximum width. Prescutellar pit elongate (Fig. 13E). [Antenna 17-segmented. Body length $2.1 \mathrm{~mm}$. USA]

S. incisa Gahan, 1912

- First metasomal tergite 2.0 times as long as its apical width. Second flagellar segment 2.0 times and sixth segment 1.7 times as long as their maximum width. Mandible 1.2 times as long as its maximum width. Prescutellar pit oval(Fig. 13F). [Antenna 19-segmented. Body length $1.6 \mathrm{~mm}$. Canada, USA] ...

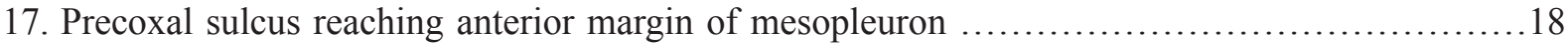

- Precoxal sulcus not reaching anterior margin of mesopleuron ............................... 19

18. Propodeal spiracles large, length of spiracle 1.3 times as long as the distance between spiracle and anterior border of propodeum (Fig. 14A). Mandible 1.4 times as long as its maximum width. Subdiscal cell 4.0 times as long as its maximum width. [Antenna 18-segmented. Body length $2.5 \mathrm{~mm}$. USA]

S. spiraculosa Fischer, 1967

- Propodeal spiracles relatively small, length of spiracle 3.0 times as long as the distance between spiracle and anterior border of propodeum (Fig. 14B). Mandible 1.2 times as long as its maximum width. Subdiscal cell 2.7 times as long as its maximum width. [Antenna 19-segmented (apical segments broken. Body length $2.1 \mathrm{~mm}$. USA] .....S. sensillosa Fischer, 1967

19. First metasomal tergite 1.4-1.9 times as long as its apical width (Figs 14C, 14D) ............20

- First metasomal tergite 2.7 times as long as its apical width (Figs 5D, 9C) .................24

20. First metasomal tergite 1.4 times as long as its apical width. Hind femur 3.3 times as long as its maximum width. Hind tibia 7.0 times as long as its maximum width. [Antenna 15 -segmented. Body length $1.6 \mathrm{~mm}$. USA]

S. megaseliae Fischer, 1967

- First metasomal tergite 1.7-1.9 times as long as its apical width. Hind femur 3.6-4.0 times as long as its maximum width. Hind tibia 7.6-8.3 times as long as its maximum width. .21

21. First flagellar segment 3.7 times, second segment 2.4 times and sixth segment 2.3 times as long as their maximum width. Eye in lateral view 1.5 times as long as temple medially. Clypeus 2.3 times 
as wide as high (Fig. 14E). First metasomal tergite paler than second and third tergites. [Antenna 21-segmented. Body length $1.3 \mathrm{~mm}$. USA] ..........................S. liliputana Fischer, 1967

- First flagellar segment 2.1-2.5 times, second segment 1.3-1.7 times and sixth segment 1.3-1.6 times as long as their maximum width. Eye in lateral view 1.0-1.3 times as long as temple medially. Clypeus 2.6-2.9 times as wide as high (Fig. 14F). First metasomal tergite similar colour as second and third tergites
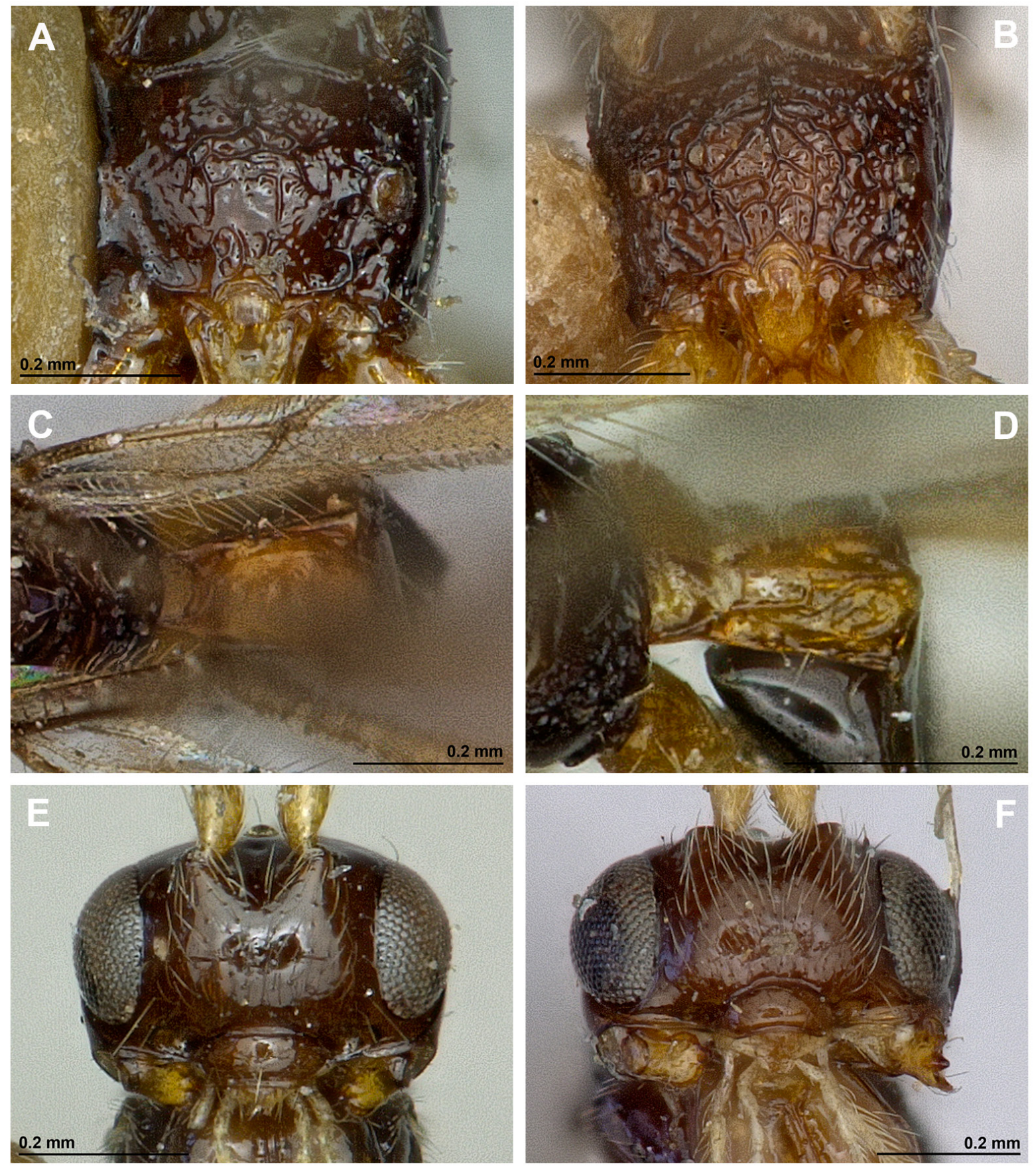

Fig. 14. A. Propodeum of Synaldis spiraculosa Fischer, 1967, dorsal view. B. Mesonotum of S. sensillosa Fischer, 1967, dorsal view. C. First metasomal tergite of S. megaseliae Fischer, 1967, dorsal view. D. First metasomal tergite of S. liliputana Fischer, 1967, dorsal view. E. Head of S. liliputana Fischer, 1967, front view. F. Head of S. altera Fischer, 1967, front view. 
22. Propodeal spiracles large, length of spiracle 1.5 times as long as the distance between spiracle and anterior border of propodeum (Fig. 15A). Subdiscal cell 3.7 times as long as its maximum width. [Antenna23-segmented (apical segments broken). Body length $2.3 \mathrm{~mm}$. USA] ...S. altera Fischer, 1967

- Propodeal spiracles relatively small, length of spiracle 3.0-3.6 times as long as the distance between spiracle and anterior border of propodeum (Fig. 15B). Subdiscal cell 2.4-3.0 times as long as its maximum width. [Antennae 17-segmented] ....

23. Face 2.0 times as wide as high. First flagellar segment 2.1 times as long as its maximum width. Mesoscutal pit round (Fig. 15C). Subdiscal cell 3.8 times as long as its maximum width. [Body length $1.8 \mathrm{~mm}$. USA]

S. difficilis Fischer, 1967

- Face 1.5 times as wide as high. First flagellar segment 2.5 times as long as its maximum width. Mesoscutal pit elongate (Fig. 15D). Subdiscal cell 5.0 times as long as its maximum width. [Body length $2.1 \mathrm{~mm}$. USA]

S. numerosa Fischer, 1967

24. Face 1.8 times as wide as high (Fig. 4E). Second flagellar segment 2.2 times and sixth segment 1.8 times as long as their maximum width (Fig. 4D). Hind femur 3.5 times as long as its maximum width (Fig. 5E). [Antenna 23-25-segmented. Body length 2.4-2.7 mm. Brazil]

S. fritzi Peris-Felipo, sp. nov.

- Face 1.2 times as wide as high (Fig. 8E). Second flagellar segment 2.7 times and sixth segment 2.5 times as long as their maximum width (Fig. 8D). Hind femur 3.9 times as long as its maximum width (Fig. 9D). [Antenna20-segmented. Body length $1.7 \mathrm{~mm}$. Brazil] ...S. magnioculis Peris-Felipo, sp.nov.
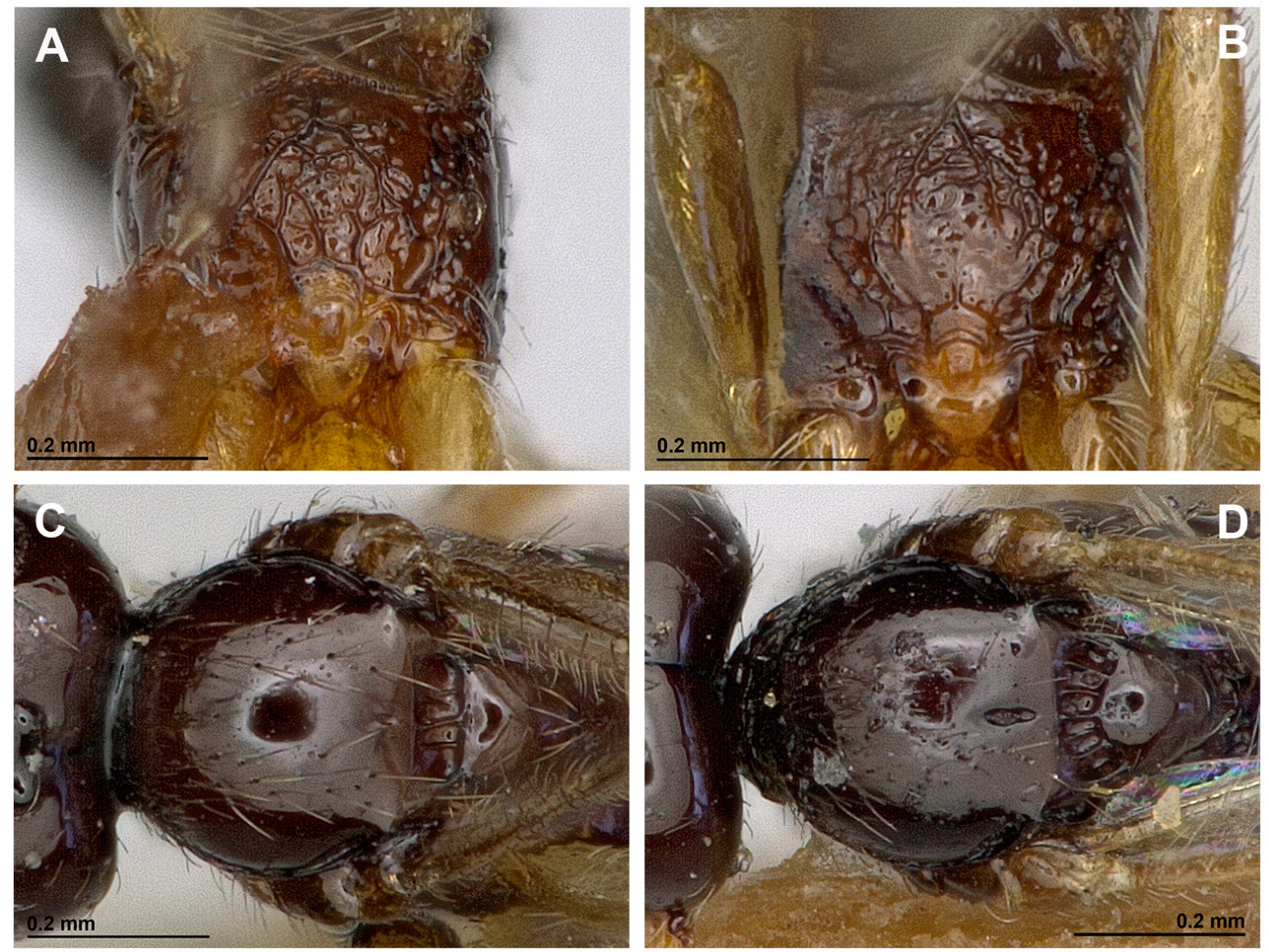

Fig. 15. A. Propodeum of Synaldis altera Fischer, 1967, dorsal view. B. Propodeum of S. difficilis Fischer, 1967, dorsal view. C. Mesonotum of S. difficilis Fischer, 1967, dorsal view. D. Mesonotum of S. numerosa Fischer, 1967, dorsal view. 


\section{Discussion}

Species of the genus Synaldis are parasitoids of Diptera, ovipositing into larvae and emerging from puparia, and have already been recorded in many zoogeographical regions of the world (Afrotropical, Australasian, Holarctic and Oriental). However, information about this group in the Neotropical region began to appear only recently (see, e.g., Peris-Felipo \& Belokobylskij 2016). The discovery of the genus Synaldis in South America is more evidence for the wide global distribution of this genus.

Despite a rather limited number of morphological characters used for species diagnoses in the Aspilota group, their combination allows a reliable discrimination of species in each region, including a highly diverse and species-rich territory such as Brazil. It is important to underline that, even in the Neotropics, members of the Aspilota group (including Synaldis) morphologically do not strongly deviate from the main and well-known diagnostic structures. This is also demonstrated for the five Neotropical Synaldis species described here: S. brasiliense sp. nov., S. fritzi sp. nov., S. longiflagellaris sp. nov., $S$. novateutoniae sp. nov., and $S$. magnioculis sp. nov. have a predominantly black body with pale legs, one of the four known types of propodeum sculpture, a similar type of wing venation, and a short and upcurved ovipositor.

The first original key for determination of all New World Synaldis species published in this paper is a very important step for a future deeper study of the biodiversity of this group of Alysiinae in the Neotropical region.

Finally, it is important to remark that the limited number of known Alysiinae taxa in the Neotropical region is a reflection of the very limited research carried out on this group to date. Further investigation both on the fauna and host associations of the Neotropical Alysiinae will be necessary to provide real information about the biodiversity of one of the world's most important regions of biota.

\section{Acknowledgement}

We are very thankful to Gavin Broad, the Natural History Museum (London, UK), for his kindness during our stay in London and to Robert Kula, Smithsonian National Museum of Natural History (Washington, USA), for providing us with type material for study. We want to sincerely thank Dominique Zimmermann and Maximilian Fischer, Naturhistorisches Museum (Vienna, Austria), for their gentleness and facilities during our stay in Vienna; Isabelle Zuecker and Daniel Burckhardt, Naturhistorisches Museum (Basel, Switzerland), for their kindness and help during our work with the photosystem. The second author was partly supported by a grant from the Russian Foundation for Basic Research (project No. 16-04-00197) and the Russian State (research project No. 01201351189).

\section{References}

Ashmead W.H. 1889. Descriptions of new Braconidae in the collection of the U.S. National Museum. Proceedings of the United States National Museum 11: 611-671. https://doi.org/10.5479/si.00963801.11-760.611

Belokobylskij S.A. 2002. Eastern Palaearctic species of the braconid wasp genus Synaldis Förster (Hymenoptera, Braconidae, Alysiinae). Species without mesoscutal pit. Entomological Review 82: 404-423.

Belokobylskij S.A. 2004a. Eastern Palaearctic species of the braconid wasp genus Synaldis Förster (Hymenoptera, Braconidae, Alysiinae). Species with mesoscutal pit: I. Entomological Review 84 (2): 191-215. 
Belokobylskij S.A. 2004b. Eastern Palaearctic species of the braconid wasp genus Synaldis Förster (Hymenoptera, Braconidae, Alysiinae). Species with mesoscutal pit: I. Entomological Review 84: 935945.

Belokobylskij S.A. \& Tobias V.I. 2007. Fam. Braconidae. Subfam. Alysiinae. Group of genera closed to Aspilota. In: Lelej A.S. (ed.). Key to insects of the Russian Far East. Neuropteroidea, Mecoptera, Hymenoptera: 9-133. Dal'nauka, Vladivostok. [In Russian.]

Beyarslan A. \& Inanç F. 1992. Turkish Alysiinae (Hymenoptera: Braconidae). II ${ }^{\text {nd }}$ Entomoloji Kongrei: 661-670. [In Turkish.]

Fischer M. 1962. Das Genus Synaldis Foerster. Mitteilungen aus dem Zoologischen Museum in Berlin 38: $1-21$.

Fischer M. 1967a. Revision der burgenlandischen Arten der Gattungen Synaldis, Aphaereta und Alysia (Hymenoptera, Braconidae, Alysiinae). Wissenschaftliche Arbeiten aus dem Burgenland 38: 92-135.

Fischer M. 1967b. Die nearktischen Arten der Gattung Synaldis Foerster (Hymenoptera, Braconidae, Alysiinae). Polskie Pismo Entomologiczne 37: 431-478.

Fischer M. 1971. Uber nordamerikanische Arten der Gattungen Orthostigma Ratzeburg und Aspilota Foerster (Hymenoptera, Braconidae, Alysiinae). Acta Entomologica Musei Nationalis Pragae 38: 81114.

Fischer M. 1993a. Zur Formenvielfalt der Kieferwespen der Alten Welt: Über die Gattungen Synaldis Foerster, Trisynaldis Fischer und Kritscherysia Fischer gen. nov. (Hymenoptera, Braconidae, Alysiinae). Annalen des Naturhistorischen Museums in Wien B 94-95: 451-490.

Fischer M. 1993b. Eine neue Studie über Buckelfliegen-Kieferwespen: Synaldis Foerster und Dinotrema Foerster (Hymenoptera, Braconidae, Alysiinae). Linzer Biologische Beiträge 25: 565-592.

Fischer M. 2003. Ein Beitrag zur Kenntnis der Gattungen Synaldis Foerster und Adelphenaldis Fischer, gen. nov. (Hymenoptera, Braconidae, Alysiinae). Linzer Biologische Beiträge 35: 19-74.

Fischer M. 2005. Eine neue gezogene Synaldis-Art aus Deutschland (Hymenoptera, Braconidae, Alysiinae). Zeitschrift der Arbeitsgemeinschaft Österreichischer Entomologen 57: 93-95.

Hussey N.W. 1960. Biology of mushroom phorids. Mushroom Science 4: 260-270.

Papp J. 1996. Braconidae (Hymenoptera) from Korea, XVIII. Annales Historico-Naturales Musei Nationalis Hungarici 88: 145-170.

Papp J. 2000. Braconidae (Hymenoptera) from Mongolia, XIV: Doryctinae, Helconinae, Meteorinae, Euphorinae, Blacinae, Opiinae and Alysiinae. Acta Zoologica Academiae Scientiarum Hungaricae 46: $35-52$.

Peris-Felipo F.J. \& Belokobylskij S.A. 2016. First record of the genus Dinotrema Foerster, 1862 (Hymenoptera, Braconidae, Alysiinae) from the Neotropical region, with description of four new species and a key to the New World taxa. European Journal of Taxonomy 179: 1-23.

https://doi.org/10.5852/ejt.2016.179

Peris-Felipo F.J., Belokobylskij S.A. \& Jiménez-Peydró R. 2014a. Revision of the Western Palaearctic species of the genus Dinotrema Foerster, 1862 (Hymenoptera, Braconidae, Alysiinae). Zootaxa 3885: 1-483. https://doi.org/10.11646/zootaxa.3885.1.1

Peris-Felipo F.J., Broad G.R., Belokobylskij S.A. \& Jiménez-Peydró R. 2014b. Three new Adelphenaldis species (Hymenoptera: Braconidae: Alysiinae) from Africa, with first descriptions of the female of A. subsurrectionis (Fischer) and the male of A. claricornis. African Entomology 22: 561-576. 
Van Achterberg C. 1988. The genera of the Aspilota-group and some descriptions of fungicolous Alysiini from the Netherlands (Hymenoptera: Braconidae: Alysiinae). Zoologische Verhandelingen 247: 1-88.

Van Achterberg C. 1993. Illustrated key to the subfamilies of the Braconidae (Hymenoptera: Ichneumonoidea). Zoologische Verhandelingen 283: 1-189.

Yu D.S., van Achterberg C. \& Horstman K. 2012. Taxapad 2012, Ichneumonoidea 2011. Database on flash-drive. Ottawa, Ontario, Canada.

Manuscript received: 28 October 2016

Manuscript accepted: 3 May 2017

Published on: 21 December 2017

Topic editor: Gavin Broad

Desk editor: Kristiaan Hoedemakers

Printed versions of all papers are also deposited in the libraries of the institutes that are members of the EJT consortium: Muséum national d'Histoire naturelle, Paris, France; Botanic Garden Meise, Belgium; Royal Museum for Central Africa, Tervuren, Belgium; Natural History Museum, London, United Kingdom; Royal Belgian Institute of Natural Sciences, Brussels, Belgium; Natural History Museum of Denmark, Copenhagen, Denmark; Naturalis Biodiversity Center, Leiden, the Netherlands; Museo Nacional de Ciencias Naturales-CSIC, Madrid, Spain; Real Jardín Botánico de Madrid CSIC, Spain. 